This document was prepared in conjunction with work accomplished under Contract No. DE-AC09-96SR18500 with the U. S. Department of Energy.

\title{
DISCLAIMER
}

This report was prepared as an account of work sponsored by an agency of the United States Government. Neither the United States Government nor any agency thereof, nor any of their employees, nor any of their contractors, subcontractors or their employees, makes any warranty, express or implied, or assumes any legal liability or responsibility for the accuracy, completeness, or any third party's use or the results of such use of any information, apparatus, product, or process disclosed, or represents that its use would not infringe privately owned rights. Reference herein to any specific commercial product, process, or service by trade name, trademark, manufacturer, or otherwise, does not necessarily constitute or imply its endorsement, recommendation, or favoring by the United States Government or any agency thereof or its contractors or subcontractors. The views and opinions of authors expressed herein do not necessarily state or reflect those of the United States Government or any agency thereof. 


\section{UNREVIEWED DISPOSAL QUESTION EVALUATION: SUBSIDENCE STUDY FOR NON-CRUSHABLE CONTAINERS IN SLIT TRENCHES (U)}

Thong Hang, Leonard B. Collard, and Mark A. Phifer

March 15, 2005

Westinghouse Savannah River Company Savannah River National Laboratory Aiken, SC 29808

Prepared for the U.S. Department of Energy Under Contract Number DEAC09-96SR18500

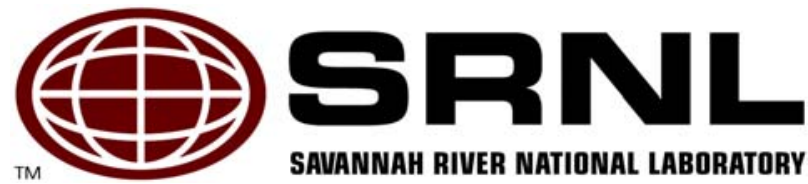


This page was intentionally left blank 


\section{EXECUTIVE SUMMARY}

This study addresses the issue of waste and cover subsidence caused by corrosion of the non-crushable waste containers defined as containers with significant void space that will not be stabilized by dynamic compaction of the E-Area Slit Trenches. Concentrations at the hypothetical 100-m well were evaluated for 1,000 years and compared with the base case value for compliance.

To generalize the results, a hypothetical, no-decay radionuclide characterized by a $\mathrm{Kd}(5 \mathrm{ml} / \mathrm{g})$ that would be most problematic was selected. The vadose zone analyses employed two distinct modeling grid layouts to better account for dissimilar flow fields between the edge trench and the middle or crest trench. These grid layouts provide higher-fidelity simulations of the actual trenches, and therefore would deliver more accurate flow fields and activity fluxes. As in the 2004 Special Analysis performed by Collard and Hiergesell (Collard and Hiergesell 2004), the waste zone thickness was modeled as a variable that changes from $16 \mathrm{ft}$ (before subsidence) to $2.5 \mathrm{ft}$ (after subsidence). Although the non-crushable containers will not be stabilized by dynamic compaction, these containers will gradually corrode, eventually collapse after placement of the final closure cap and cause the cap to subside resulting in an increase of the infiltration rates. Using the HELP model, infiltration rates for each trench (i.e., edge trench, middle trench and crest trench) were estimated for both intact and subsided conditions over a 10,000-year period. Applying these infiltration rates in all time intervals up to 1,000 years, steady-state flow fields were generated for all scenarios.

For a better representation of the waste footprint, an aquifer model with a refined mesh of $20 \mathrm{ft} x 20 \mathrm{ft}$ in plan view was designed. The 2004 Special Analysis used a coarser mesh of $200 \mathrm{ft} \times 200 \mathrm{ft}$. The fine mesh allows more precise allocation of contaminant source cells into each individual slit trench. This allocation scheme makes analyses of any partial or total subsidence of any trench or a combination of trenches among the slit trenches possible.

To study the potential effect of trench subsidence on the well concentrations within the 1,000-yr time window, two high-impact cases were considered. In the first case, trenches subsided right after dynamic compaction (i.e., at 125 years). In the second case, trenches subsided at 419 years to make the peak concentrations from both the subsided and unsubsided area align in space and time.

The study shows that the first case presented no compliance problem for the subsidence of up to two trenches. In the second case, even a single trench subsidence caused the well concentration to be out of compliance. The peak concentration exceeded the base case value by $9 \%$ (subsidence of $14-5$ trench) and $15 \%$ (subsidence of $14-5$ and $14-4$ trenches)

Wilhite (2003) states that "DOE guidance for PA maintenance establishes a criterion for the significance of changes in PA results. The criterion is that changes of about 10 percent in the dose or impact are considered to be insignificant." Using this criterion, the following recommendations are made:

1. In general, the amount of the waste area that contains non-crushable containers should not exceed 10 percent for two adjacent Slit Trench disposal units. The waste area is defined as the trench area where waste is disposed, not the overall area of the disposal unit. This requirement can be satisfied in either of two ways:

a. Each Slit Trench disposal unit does not exceed 10 percent, or

b. If one Slit Trench disposal unit exceeds 10 percent, then when combined with each neighboring disposal unit, the combination does not exceed 10\%. For example if the waste area that contains non-crushable containers is $15 \%$ for one disposal unit, then neither adjacent disposal unit can exceed 5\%. 
2. If the amount of the waste area that contains non-crushable containers exceeds 10 percent for two adjacent Slit Trench disposal units and requirement 1 above is not satisfied, then the allowable non-crushable percent area can be increased from $10 \%$ to a maximum of $20 \%$. If the allowable non-crushable percent area is increased to more than $10 \%$, then the maximum allowable sum-of-fractions must be reduced by multiplying by $0.87(1 / 1.15)$. This requirement only applies to groundwater pathway time intervals that occur after placement of the final cover (currently 125 years). The groundwater pathway time intervals are as follow:

a. GW1 -0 to 12 years

b. GW2 -12 to 100 years

c. GW3 - 100 to 1000 years.

Therefore, this requirement for current limits only applies to GW3. 
TABLE OF CONTENTS

EXECUTIVE SUMMARY

LIST OF FIGURES

LIST OF TABLES

1. INTRODUCTION

2. MODELING APPROACH

2.1 Vadose Zone Model

2.2 Aquifer Model

2.3 Scenarios

3. RESULTS

iii

3.1 Evaluation

4. CONCLUSIONS

vi

vi

5. RECOMMENDATIONS

6. REFERENCES

APPENDIX A. E-AREA SLIT TRENCH INFILTRATION ESTIMATES

APPENDIX B. DESIGN CHECKS 


\section{LIST OF FIGURES}

Figure 1. Slit Trench arrangement .................................................................................. 3

Figure 2. Vadose zone modeling grid for edge trench......................................................... 4

Figure 3. Vadose zone modeling grid for middle/crest trench..................................................... 5

Figure 4. Effect of $\mathrm{Kd}$ on the fractional flux at the water table (Edge trench) ............................... 6

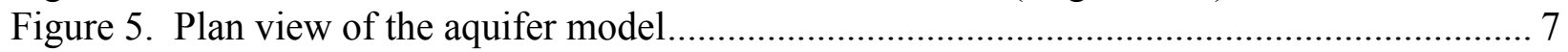

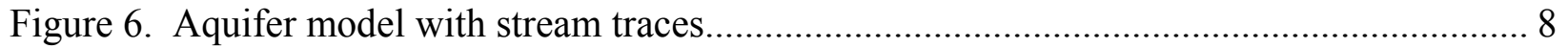

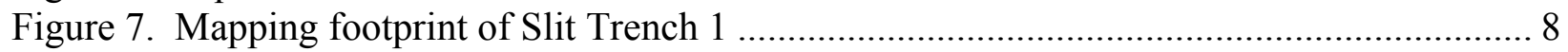

Figure 8. Mapping footprint of slit trenches onto aquifer model source cells ............................... 9

Figure 9. Location of peak concentration on the Slit Trench perimeter ...................................... 10

Figure 10. Fractional fluxes at the water table (Base case) …………......................................... 12

Figure 11. Well concentration (Base case) ......................................................................... 12

Figure 12. Well concentration (Trench subsidence at 125 years) ................................................ 13

Figure 13. Fractional flux at the water table (ST1-5 subsidence at 419 years) ............................ 13

Figure 14. Well concentration (ST1-5 subsidence at 419 years) ............................................... 14

Figure 15. Well concentration (Trench subsidence at 419 years)................................................ 14

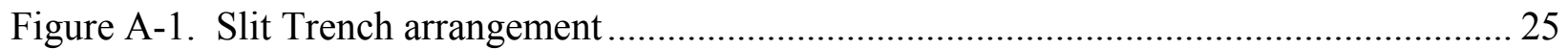

\section{LIST OF TABLES}

Table 1. Modeled infiltration rates and time intervals ............................................................... 3

Table 2. Material properties for vadose zone flow and transport analyses.................................... 5

Table 3. Summary of peak well concentrations ........................................................................ 15

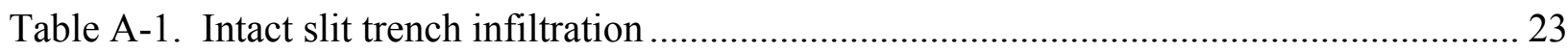

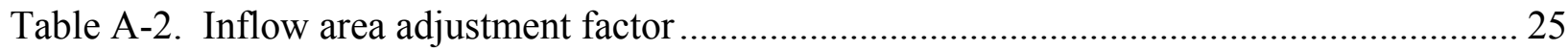

Table A-3. Crest trench subsided infiltration.................................................................................. 26

Table A-4. Middle trench subsided infiltration with no upslope subsidence ............................... 26

Table A-5. Middle trench subsided infiltration with subsidence of the crest trench .................... 27

Table A-6. Edge trench subsided infiltration with no upslope subsidence .................................. 27

Table A-7. Edge trench subsided infiltration with subsidence of the crest trench ....................... 28

Table A-8. Edge trench subsided infiltration with subsidence of the middle trench.................... 28

Table A-9. Edge trench subsided infiltration with subsidence of both the crest and middle

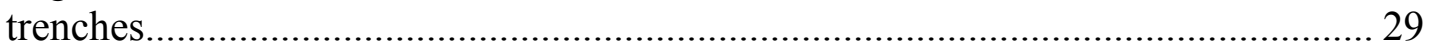

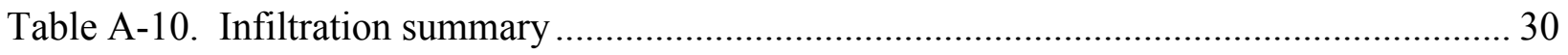




\section{INTRODUCTION}

The Closure Plan for the E-Area low-level waste facility (Cook et al. 2004) assumes that dynamic compaction performed at the end of the 100-year institutional control period will adequately stabilize all waste in Slit Trenches. However, some non-crushable waste containers with significant void space will not be stabilized by dynamic compaction. These non-crushable containers will gradually corrode, eventually collapse and cause the final closure cap to subside resulting in an increase of the infiltration rates (Phifer 2004). After subsidence occurs, the waste zone will be significantly reduced to concentrate waste in the lower portion of the slit trench, therefore increasing waste concentration. The trench subsidence may have an adverse impact on the 1000-year compliance specified in DOE Order 435.1 (US DOE 1999).

This study addresses the issue of trench subsidence, evaluates the resulting concentrations at the hypothetical 100-m well against those obtained based on the PA approach (Collard and Hiergesell 2004), and provides the maximum number of trenches that can subside without causing the well concentrations to be out of compliance. 
WSRC-TR-2005-00104

Revision 0

THIS PAGE INTENTIONALLY LEFT BLANK 


\section{MODELING APPROACH}

A Slit Trench disposal unit currently consists of a set of five slit trenches with each trench being 20 feet wide by 656 feet long with a 10-ft space between trenches. A set of two Slit Trench disposal units was considered in this subsidence study. The arrangement for each slit trench set is illustrated in Figure 1. All scenarios were simulated using PC-based PorFlow ${ }^{\mathrm{TM}}$ Version 5.97 (ACRi 2002).

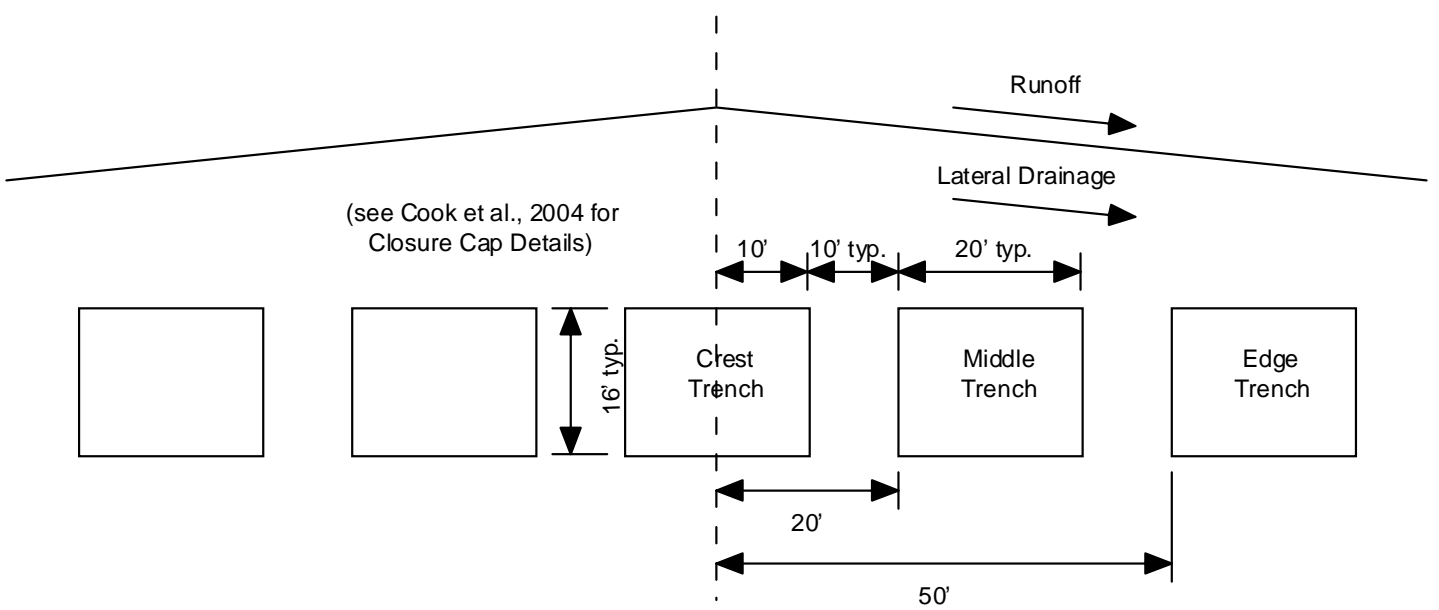

Figure 1. Slit Trench arrangement

\subsection{Vadose Zone Model}

Using the HELP model (US EPA 1994a; US EPA 1994b), infiltration rates for each trench (i.e., edge trench, middle trench and crest trench) were estimated for intact and subsided conditions over a 10,000year period. A detailed discussion of infiltration estimates is given in Appendix A. The resulting infiltration estimates are summarized in Table A-10. The vadose zone model uses the highest infiltration rates in each time interval after 125 years. This approach would produce more conservative results. Table 1 shows the modeled infiltration rates in all time intervals up to 1,025 years. Note that the first scenario in Table 1 (i.e., without any subsidence) represents the intact-condition scenario in Table A-10. In Table 1, the time intervals starting from -25 years as shown in Table A-10 were converted to the intervals with the initial time at 0 year. The total simulation time was selected to be the 1,000 -year time of compliance specified in DOE Order 435.1. Applying these infiltration rates, the steady-state flow fields were generated using PorFlow ${ }^{\mathrm{TM}}$ for each time interval of all scenarios listed in Table 1.

Table 1. Modeled infiltration rates and time intervals

\begin{tabular}{|c|c|c|c|c|c|c|c|}
\hline \multicolumn{3}{|c|}{ Subsided Trench } & \multicolumn{5}{|c|}{ Infiltration (in/yr) } \\
\hline Crest & Middle & Edge & $0-25$ yrs $^{\dagger}$ & 25-125 $\mathrm{yrs}^{\dagger+}$ & 125-325 yrs & $325-575$ yrs & $575-1025$ yrs \\
\hline No & No & No & 11.26 & 0.36 & 3.05 & 7.90 & 12.04 \\
\hline Yes & No & No & 11.26 & 0.36 & 15.91 & 15.91 & 15.91 \\
\hline No & Yes & No & 11.26 & 0.36 & 27.36 & 24.97 & 20.80 \\
\hline Yes & Yes & No & 11.26 & 0.36 & 21.27 & 20.20 & 18.36 \\
\hline No & No & Yes & 11.26 & 0.36 & 47.77 & 41.18 & 29.28 \\
\hline Yes & No & Yes & 1126 & 0.36 & 40.85 & 35.59 & 26.36 \\
\hline No & Yes & Yes & 11.26 & 0.36 & 21.27 & 20.20 & 18.36 \\
\hline Yes & Yes & Yes & 11.26 & 0.36 & 21.27 & 20.20 & 18.36 \\
\hline
\end{tabular}

$\left(^{+}\right.$: Initial uncapped period; +": Institutional control period; $\geq 125$ years: Failed period) 
The vadose zone analyses were based on a previous special analysis (Collard and Hiergesell 2004) that incorporated the effects of dynamic compaction and subsidence. This special analysis will be referred to as the Special Analysis in this report. As shown in Figure 1, the space between trenches is 10 feet. The outer side of the edge trench is $\sim 23 \mathrm{ft}$ away from a vertical drain/barrier combination. Hence, to better account for the difference in geometry between the edge trench and the middle or crest trench, two modeling grid layouts were generated as shown in Figure 2 and Figure 3. These figures display distances in $\mathrm{cm}$ as used in the PorFlow ${ }^{\mathrm{TM}}$ vadose zone models. The Special Analysis, as in the PA vadose-zone model, employed a single modeling grid layout (i.e., Figure 2 layout) for all trenches. The two distinct grid layouts would provide more accurate trench flow fields and activity fluxes. As in the Special Analysis, the waste zone thickness was modeled as a variable: the initial waste zone (16 ft thick) and the final waste zone ( $2.5 \mathrm{ft}$ thick) that was assumed to occur after a trench subsidence. The material properties used for the vadose zone flow and transport analyses are the same as those in the Special Analysis. The data are shown in Table 2. Bold values in Table 2 highlight the change in properties before and after subsidence.

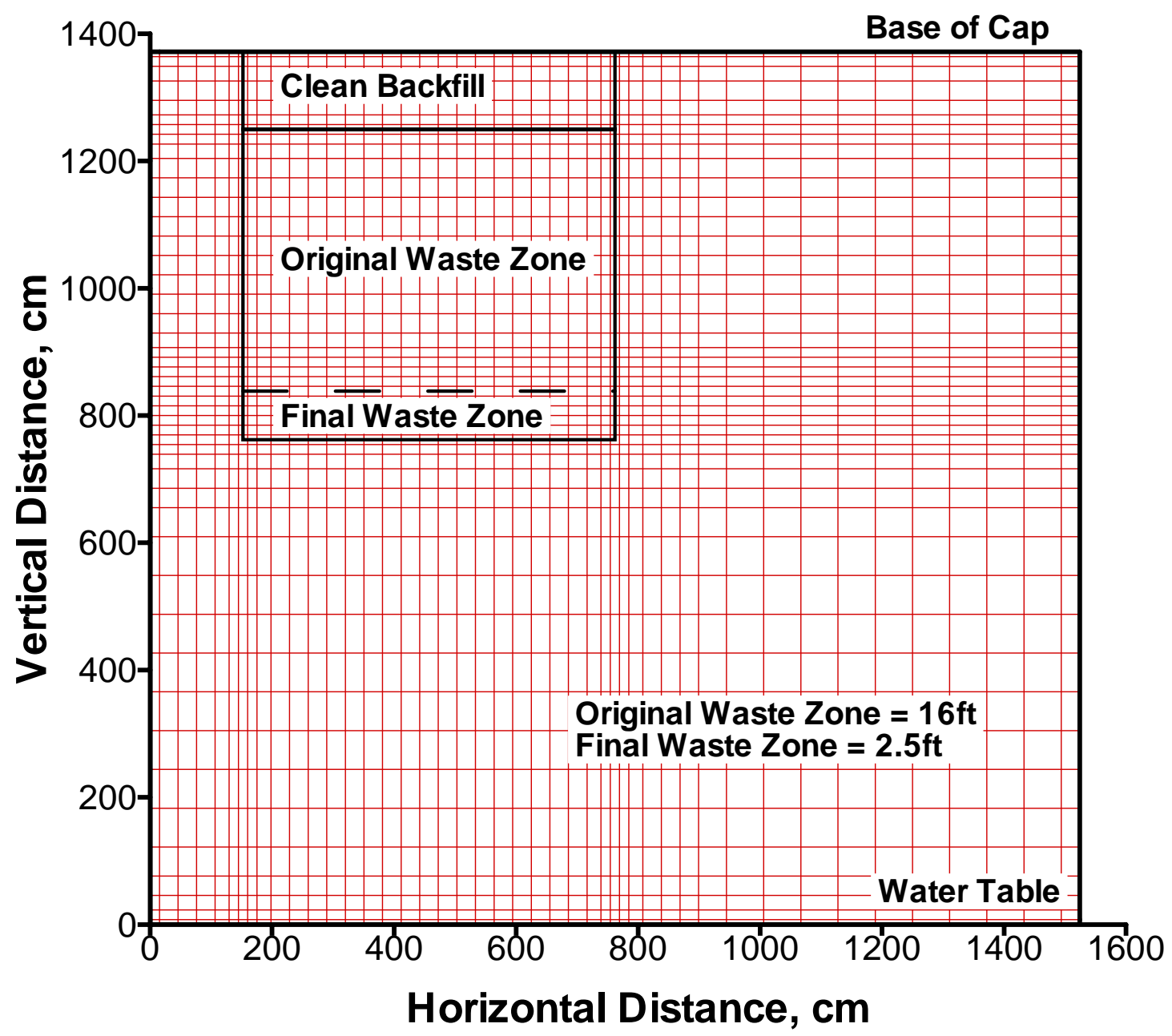

Figure 2. Vadose zone modeling grid for edge trench 
WSRC-TR-2005-00104

Revision 0

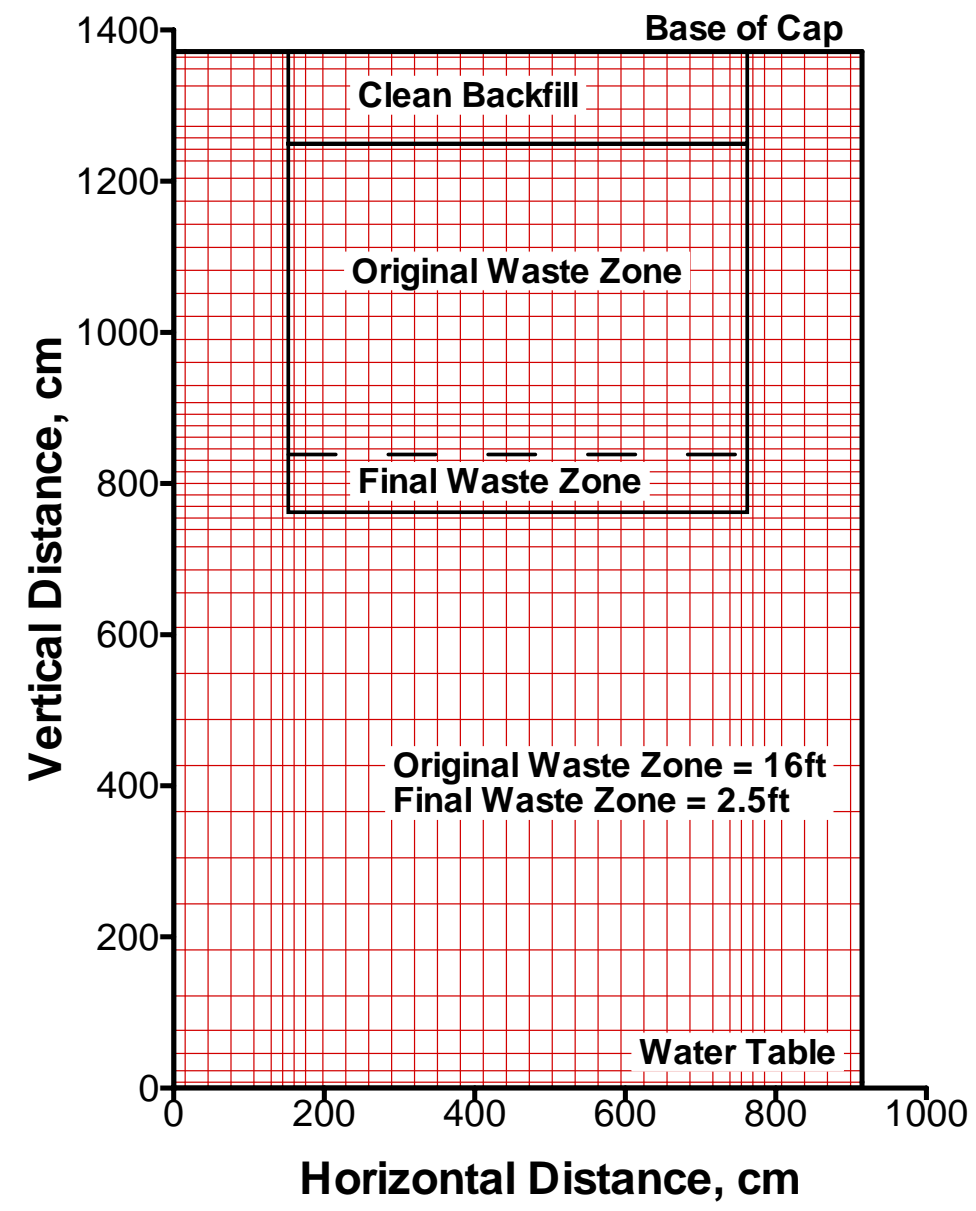

Figure 3. Vadose zone modeling grid for middle/crest trench

Table 2. Material properties for vadose zone flow and transport analyses

\begin{tabular}{|c|c|c|c|c|}
\hline Properperties & Clean Backfill & $\begin{array}{c}\text { Top } 13.5 \mathrm{ft} \text { Waste } \\
\text { Zone }\end{array}$ & $\begin{array}{l}\text { Bottom } 2.5 \mathrm{ft} \\
\text { Waste Zone }\end{array}$ & Native Soil \\
\hline $\begin{array}{l}\text { Particle density } \\
(\mathrm{g} / \mathrm{cc})\end{array}$ & 2.65 & 2.65 & 2.65 & 2.65 \\
\hline $\begin{array}{l}\text { Porosity } \\
\text { (cc/cc) } \\
\text { - Initial } \\
\text { - After subsidence }\end{array}$ & $\begin{array}{l}0.51 \\
0.51\end{array}$ & $\begin{array}{l}0.38 \\
\mathbf{0 . 5 1}\end{array}$ & $\begin{array}{l}0.38 \\
0.38\end{array}$ & $\begin{array}{l}0.42 \\
0.42\end{array}$ \\
\hline $\begin{array}{l}\text { Saturated } \\
\text { hydraulic } \\
\text { conductivity } \\
\text { ( } \mathrm{cm} / \mathrm{yr}) \\
\text { - Intial } \\
\text { - After subsidence }\end{array}$ & $\begin{array}{l}3.154 \mathrm{E} 4 \\
3.154 \mathrm{E} 3\end{array}$ & $\begin{array}{l}3.154 \mathrm{E} 5 \\
3.154 \mathrm{E} 3\end{array}$ & $\begin{array}{l}3.154 \mathrm{E} 5 \\
6.3072 \mathrm{E} 3\end{array}$ & $\begin{array}{l}3.154 \mathrm{E} 2 \\
3.154 \mathrm{E} 2\end{array}$ \\
\hline $\begin{array}{l}\text { Diffusion } \\
\text { coefficient } \\
\left(\mathrm{cm}^{2} / \mathrm{yr}\right)\end{array}$ & $1.578 \mathrm{E} 2$ & $1.578 \mathrm{E} 2$ & $1.578 \mathrm{E} 2$ & $1.578 \mathrm{E} 2$ \\
\hline $\begin{array}{l}\text { Dispersivity } \\
\text { (cm) }\end{array}$ & 0 & 0 & 0 & 0 \\
\hline
\end{tabular}


In order to generalize the results, a hypothetical, no-decay radionuclide characterized by a specific Kd was selected. Without decay the transport of the radionuclide throughout the modeling domain is primarily affected by infiltration. Therefore, the impact of trench subsidence on the well concentrations can be isolated for study.

To select a $\mathrm{Kd}$, several runs for the intact condition with no dynamic compaction were made in which $\mathrm{Kd}$ values were varied from 0 to $100 \mathrm{ml} / \mathrm{g}$. An increase in $\mathrm{Kd}$ would cause more retardation, resulting in a slower mass transport of the radionuclide in the fluid phase. Consequently, the time at which the flux at the water table peaks increases with increasing $\mathrm{Kd}$. Figure 4 displays the effect of $\mathrm{Kd}$ on the fractional flux calculated at the water table. Note that no flux for a $\mathrm{Kd}$ of $100 \mathrm{ml} / \mathrm{g}$ is visible within 1,000 years. Since a late peak time of the flux may result in a well concentration that peaks after 1,000 years, an early flux peak time would be preferable to provide flexibility to analyze the potential effect of trench subsidence within the 1,000-yr time window of interest. With a zero Kd, the fractional flux peaks at 7 years. Subsidence will not have any significant impact on the well concentrations if the flux peaks prior to placement of the final cap at 125 years. Hence, a Kd of $5 \mathrm{ml} / \mathrm{g}$ was selected in this study.

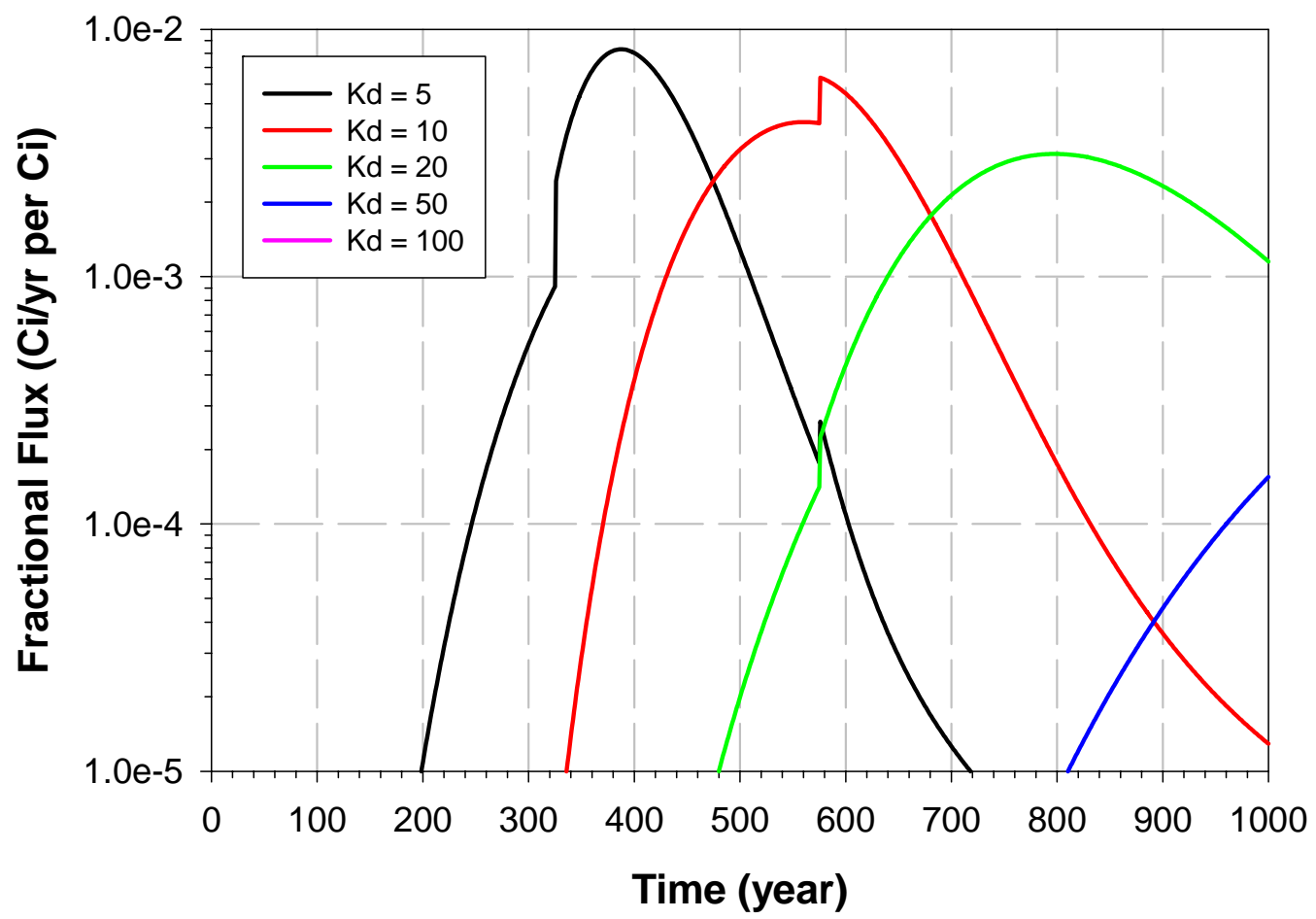

Figure 4. Effect of Kd on the fractional flux at the water table (Edge trench)

\subsection{Aquifer Model}

The aquifer model was designed to accurately represent the locations in the aquifer where the contamination from the vadose zone would first enter. For a better representation of the waste footprint, a finer mesh of $20 \mathrm{ft} \times 20 \mathrm{ft}$ in plan view was generated in comparison to the coarser mesh of $200 \mathrm{ft} \times 200 \mathrm{ft}$ used in the Special Analysis. The finer mesh allows more precise allocation of contaminant source cells into each individual slit trench. As a result, this allocation scheme makes analyses of any partial or total subsidence of any trench or a combination of trenches among the 10 slit trenches possible. Figure 5 provides a plan view of the aquifer model including the two sets of slit trenches (i.e., Slit 1 and Slit 2) and the 100-m buffer. Figure 6 shows the plan view of the aquifer model with stream traces (blue lines) 
generated from the aquifer flow field. Red circles on stream traces are 5-year pore velocity markers that start from 4 corners of the 10-trench footprint. The blue box in Figure 6 outlines the modeling domain.

Trench segments were defined by Solid Waste as portions of the five slit trenches that form disposal units Slit Trench 1 and Slit Trench 2. Solid Waste provided a drawing of the trench segments including notations that are shown in Figure 7 for Slit Trench 1 (Reed 2004). Figure 8 displays the modeled footprint of Slit Trench 1 and Slit Trench 2. The green dots in Figure 8 represent the allocated source cells. This study used a simple notation to identify each trench of two Slit Trench sets. In this notation, the trench order within each trench set increases toward the SRS north. For example, ST1-1 and ST1-5 (see Figure 8) are the lower and the upper edge trench of Slit Trench set 1, respectively.

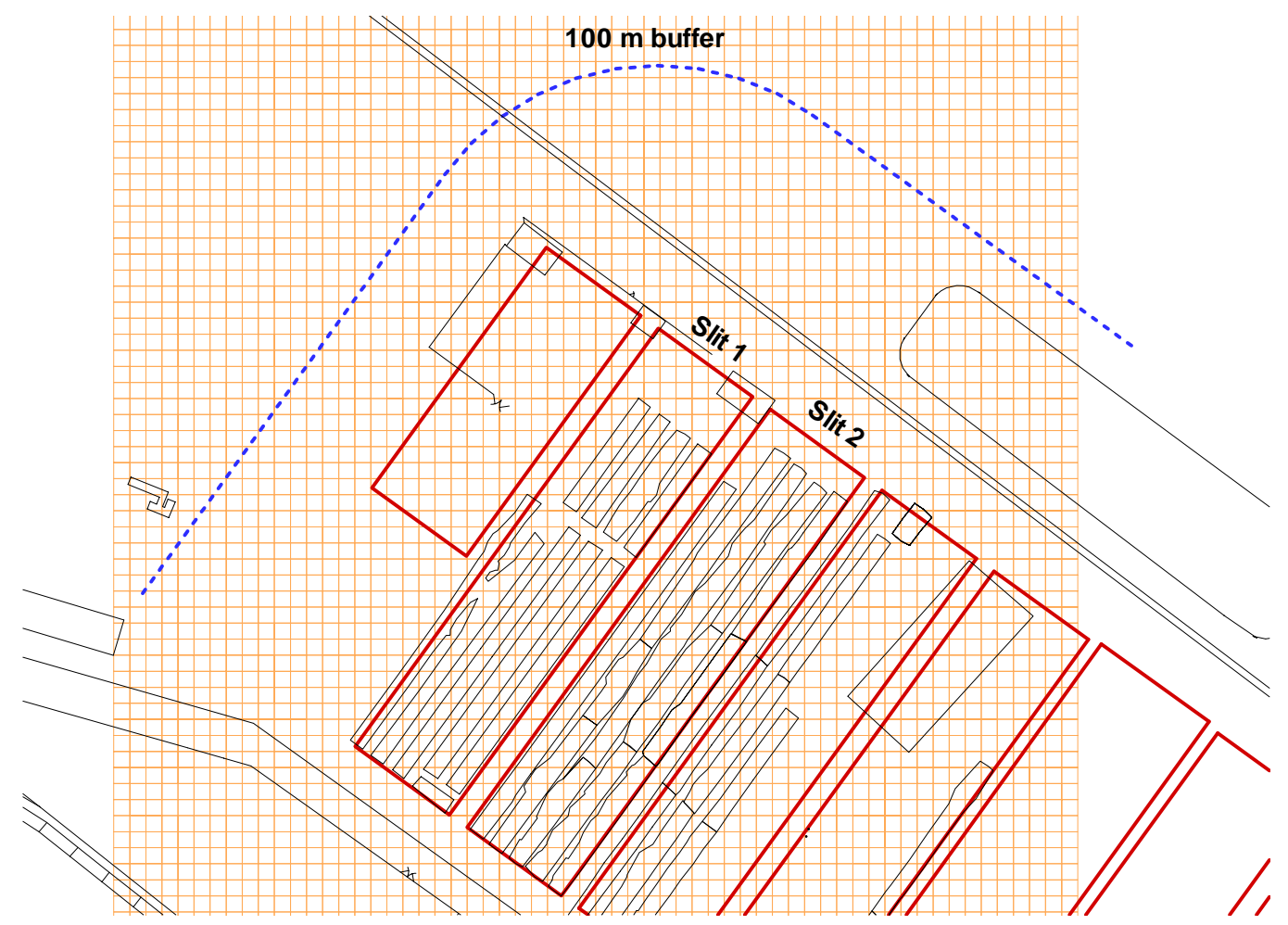

Figure 5. Plan view of the aquifer model 
WSRC-TR-2005-00104

Revision 0
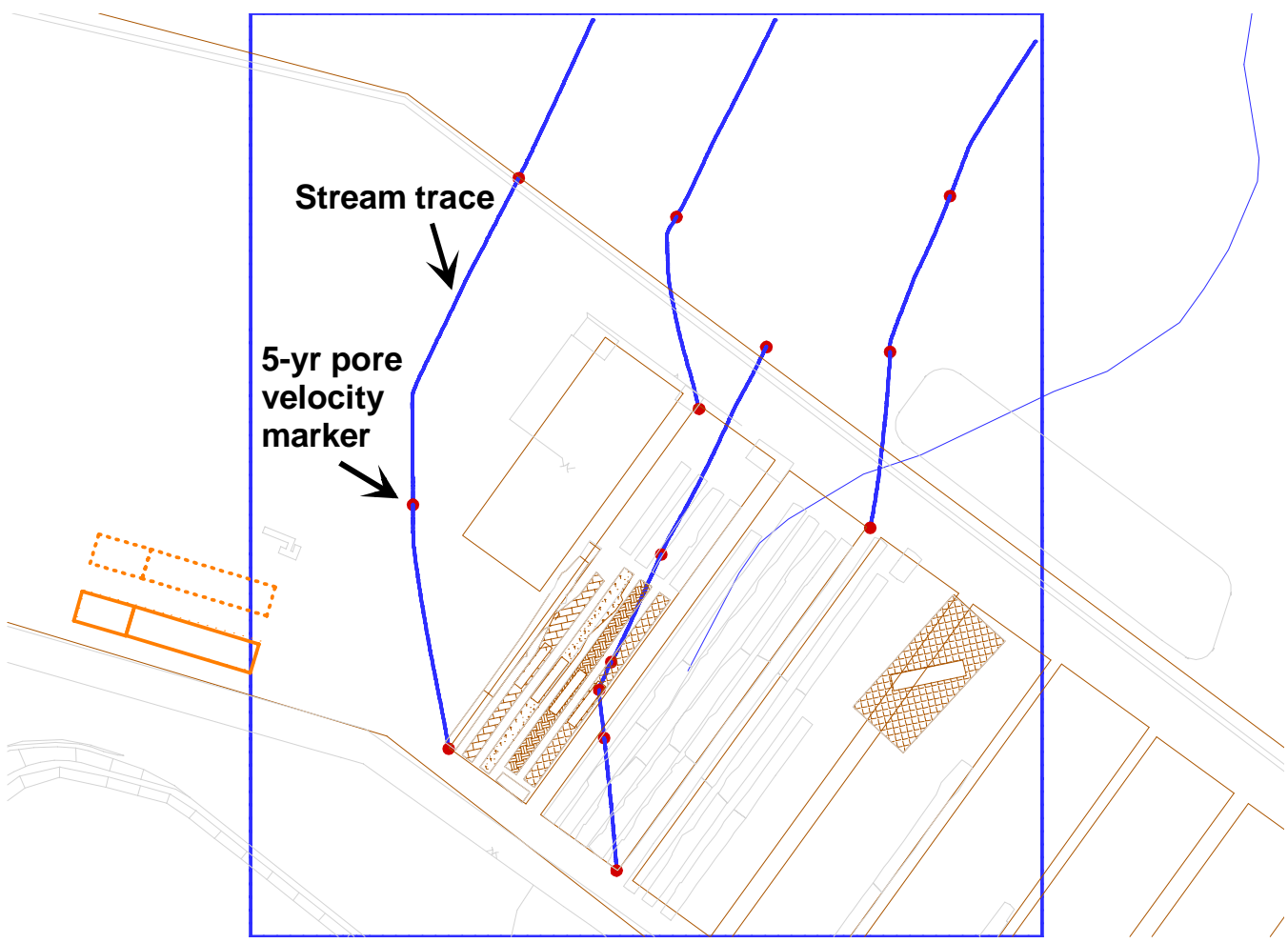

Figure 6. Aquifer model with stream traces

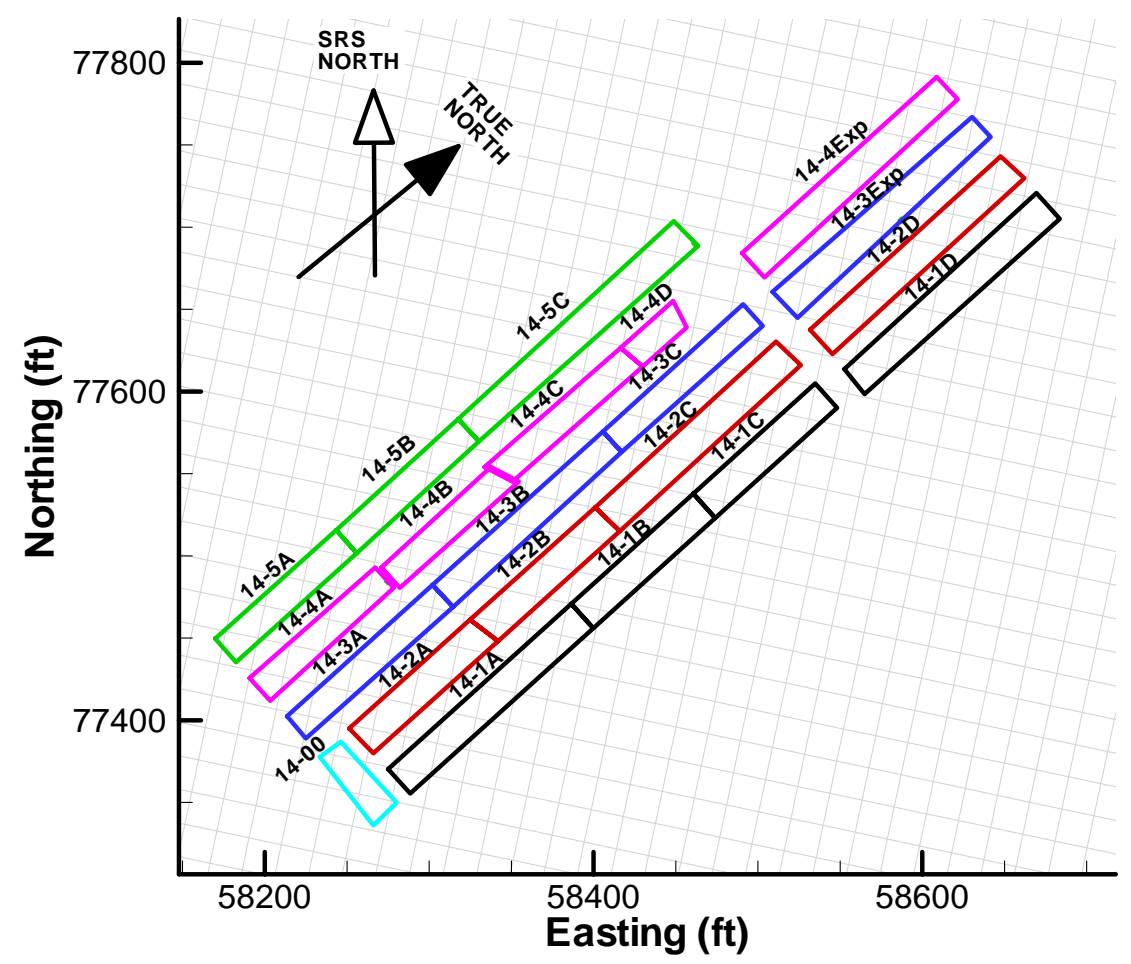

Figure 7. Mapping footprint of Slit Trench 1 


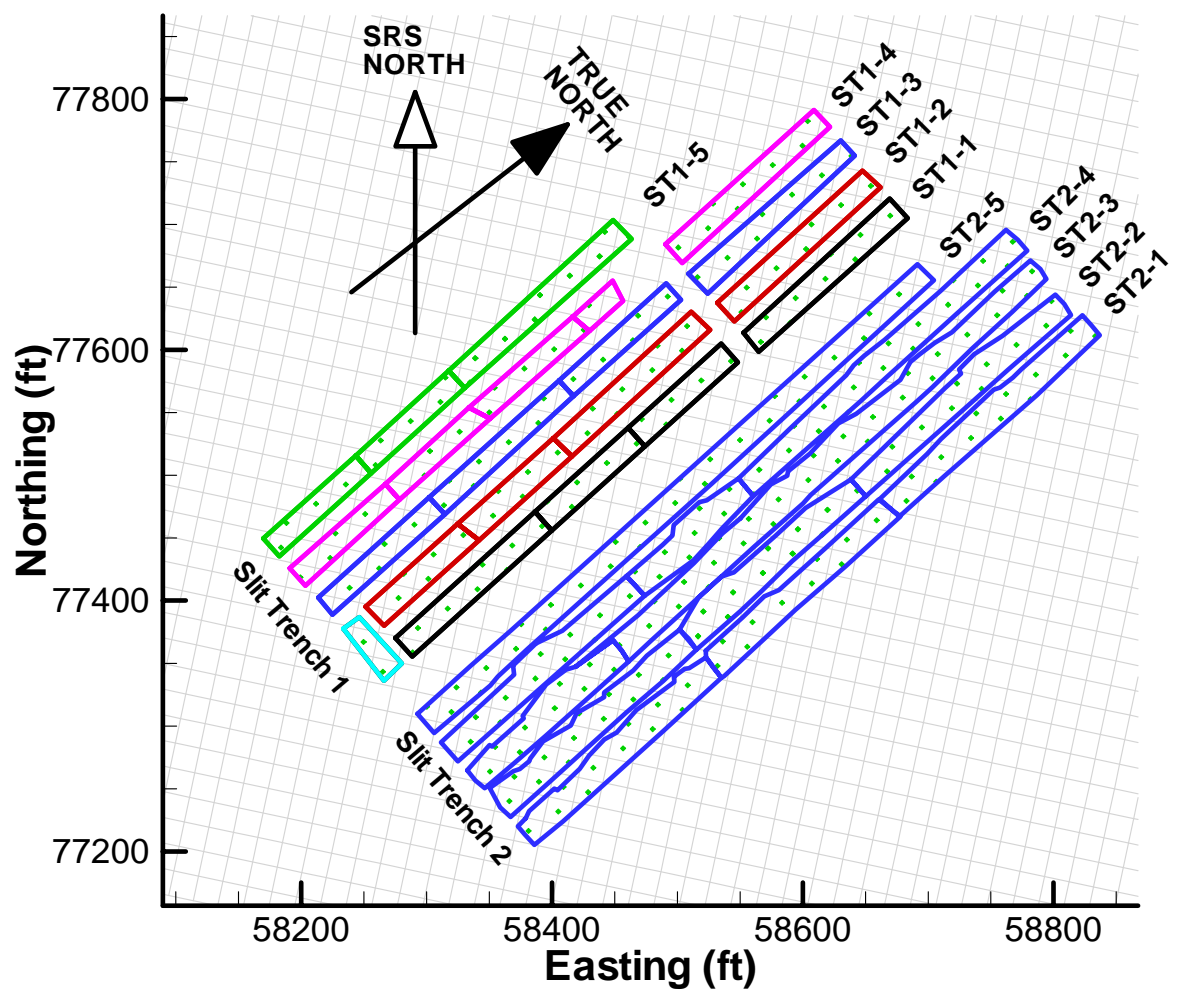

Figure 8. Mapping footprint of slit trenches onto aquifer model source cells

\subsection{Scenarios}

As learned from the Special Analysis, there are two high-impact cases that could be considered for studying the potential effect of trench subsidence on the $100-\mathrm{m}$ well concentrations within 1,000 years. In the first case, the subsided area alone produces a peak concentration that is greater than the peak concentration for the base case. In the second case, the peak concentrations from the subsided area and the unsubsided area align in space and time, resulting in a combining peak concentration exceeding the base case peak concentration.

To analyze these high-impact cases, PorFlow ${ }^{\mathrm{TM}}$ simulations were performed as outlined below. In all simulations, a hypothetical, no-decay radionuclide with a $\mathrm{Kd}$ of $5 \mathrm{ml} / \mathrm{g}$ was selected. For all cases, the assumption was made that the waste is uniformly distributed and was placed in the trenches at the beginning of the simulation.

1. Case 1: The first case was to establish a base case for comparison. Simulation was performed with dynamic compaction at 125 years and the waste zone was compacted from $16 \mathrm{ft}$ to $2.5 \mathrm{ft}$ with no trench subsidence. This same method was used in the Special Analysis.

2. Case 2: Trench subsidence occurs right after dynamic compaction (i.e., at 125 years).

Simulations were performed by increasing the number of subsided trenches until the well peak concentration exceeds the base case value.

3. Case 3: Trench subsidence occurs at the earliest time that would make the peak concentrations from the subsided area and the unsubsided area align in space and time. Again, simulations were 
performed by increasing the number of subsided trenches until the well peak concentration exceeds the base case value.

For Cases 2 and 3, trench subsidence was selected so that it would have the largest impact on contaminant concentrations in the aquifer. That could be achieved when the subsided trenches are closest to the location on the perimeter of the two slit trench disposal units at which the contaminant concentration from the unsubsided area peaks. If the subsided area is closest to the location of the peak concentration from the unsubsided area, the bulk of its contaminant concentration would pass through that location, hence resulting in the possibly highest combining concentration peak. To determine the peak concentration location, a PorFlow ${ }^{\mathrm{TM}}$ simulation was performed for the intact condition without dynamic compaction. The PorFlow ${ }^{\mathrm{TM}}$ command 'STATistics' was utilized to provide information about the peak concentration and its location over time along the Slit Trench perimeter. The peak concentration location obtained from this analysis is shown in Figure 9. The peak time at this location was determined to be 420 years. This location seems logical with respect to the direction of stream traces in Figure 6. The following trenches were selected for subsidence: (1) ST1-5 (i.e., 14-5 in Solid Waste notation) for one subsided trench, and (2) ST1-5 and ST1-4 (or 14-5 and 14-4) for two subsided trenches.

In Case 3, the time at which trenches subsided was adjusted to make the vadose zone flux at the water table peak at the same time as the peak aquifer concentration in the Slit Trench perimeter location discussed above. This subsidence time was determined to be 419 years (see Figure 13).

The vadose-zone contaminant flux to the water table was obtained for each individual trench based on an initial 1-Ci trench inventory. Because of the difference in geometry as shown in Figure 2 and Figure 3, the edge trench flux differs from the middle or crest trench flux even for the same infiltration rate. All contaminant fluxes were appropriately assigned to the aquifer source cells shown in Figure 8. This feature of the aquifer model makes analyses of a partial or total subsidence of any trench or a combination of trenches among the 10 slit trenches possible.

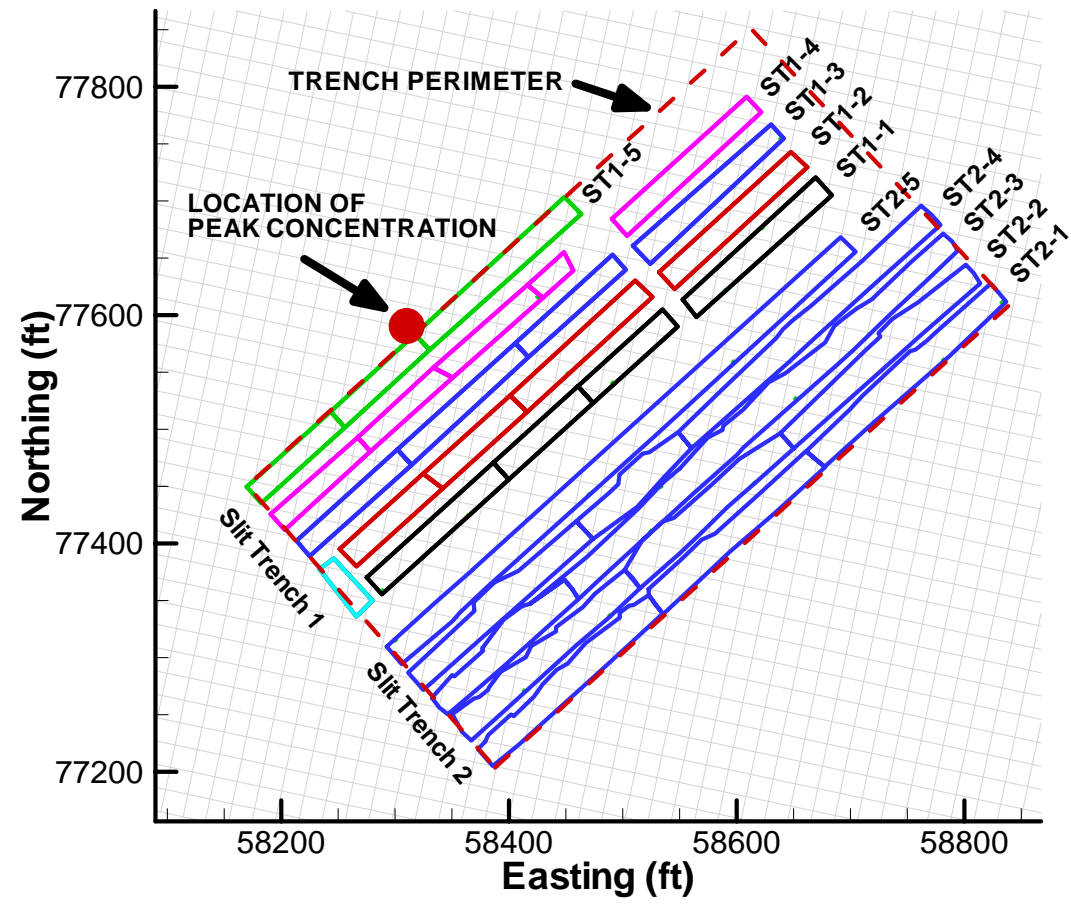

Figure 9. Location of peak concentration on the Slit Trench perimeter 


\section{RESULTS}

The fractional contaminant fluxes (i.e., fluxes per initial $\mathrm{Ci}$ inventory) at the water table (from the vadose zone models) and the concentration at the hypothetical $100-\mathrm{m}$ well where the maximum concentration occurs (from the aquifer model) are illustrated in Figure 10 and Figure 11 for the base case. Figure 10 confirms the difference between the edge and crest/middle trench fluxes due to dissimilar flow fields. PorFlow $^{\mathrm{TM}}$ simulation results revealed that starting with a $1 \mathrm{Ci}$ initial inventory the inventories remaining in the trench at 125 years were $2.63 \mathrm{E}-2 \mathrm{Ci}$ for the edge trench and $5.89 \mathrm{E}-2 \mathrm{Ci}$ for the crest/middle trench. The inventories remaining in the total modeling domain at 1,025 years were $4.98 \mathrm{E}-6 \mathrm{Ci}$ and $1.97 \mathrm{E}-5 \mathrm{Ci}$ for the edge trench and the crest/middle trench, respectively. These results clearly indicate that contaminants move out of the trench to the water table faster in the case of the edge trench, hence resulting in an earlier peak flux of the edge trench as confirmed by Figure 10. Figure 10 and Figure 11 also show that from the time of the peak flux at the water table ( $\sim 400$ years) it took $\sim 100$ years for the well concentration to peak. To be consistent with the Special Analysis, the well concentrations are expressed in $\mathrm{pCi} / \mathrm{L} / \mathrm{Ci}$ per disposal unit (i.e., set of 5 trenches). The concentration results obtained from PorFlow ${ }^{\mathrm{TM}}$ were in $\mathrm{Ci} / \mathrm{ft}^{3}$. Because the initial inventory is $1 \mathrm{Ci}$ per trench, resulting in a total inventory of $10 \mathrm{Ci}$ for two Slit Trench sets, the well concentrations per Slit Trench inventory are calculated from PorFlow ${ }^{\mathrm{TM}}$ results as follows:

Concentration $(\mathrm{pCi} / \mathrm{L} / \mathrm{Ci})=$

$$
\mathrm{C}\left(\mathrm{Ci} / \mathrm{ft}^{3}\right) * 1 \mathrm{E}+12(\mathrm{pCi} / \mathrm{Ci}) *[2(\text { Disposal Units }) / 10 \mathrm{Ci}] / 28.31685\left(\mathrm{~L} / \mathrm{ft}^{3}\right)
$$

For Case 2 in which trench subsidence occurs at 125 years the well concentrations are shown in Figure 12. Subsidence of a single trench (Edge trench ST1-5) and two trenches (Edge trench ST1-5 and middle trench ST1-4) were simulated. For each type of subsidence, the calculated well concentrations exhibit two peaks resulting from the subsided area (first peak) and the unsubsided area (second peak). The second peaks align in time with the peak from the base case that was simulated with no trench subsidence. A single trench subsidence presented no compliance problem, since the peak well concentrations were less than the base case peak value. When two trenches subsided, the first peak concentration was slightly higher than the base case value. Note that the second well-concentration peak was much lower than the first, because less contaminant remained in the modeling domain when the second peak occurred. In Figure 12, to capture the peak concentration values, the well concentrations were monitored at different well locations, i.e., at element 45021 for the base case, at element 41128 for the ST1-5 subsidence, and at element 44657 for the ST1-4/ST1-5 subsidence. As a result, the different behavior was observed between cases.

In Case 3, the impact of trench subsidence at a later time after dynamic compaction was studied. The aquifer concentration from the unsubsided area peaked at the trench perimeter location shown in Figure 9. The peak time was determined to be 420 years. For the vadose zone flux at the water table to peak at 420 years, the subsidence time of 419 years was selected as shown in Figure 13. In case of a single trench (Edge trench ST1-5) subsidence, the subsided area contributed $\sim 30 \%$ of the peak well concentration (see Figure 14). Figure 15 indicates when the peak concentrations from the subsided area and the unsubsided area align in space and time, even a single trench subsidence would cause the well concentration to be out of compliance.

Peak values and peak times for the 100-m well concentration are summarized in Table 3 for all scenarios. The extent (in \%) to which the peak well concentration exceeded the base case value is also provided. 


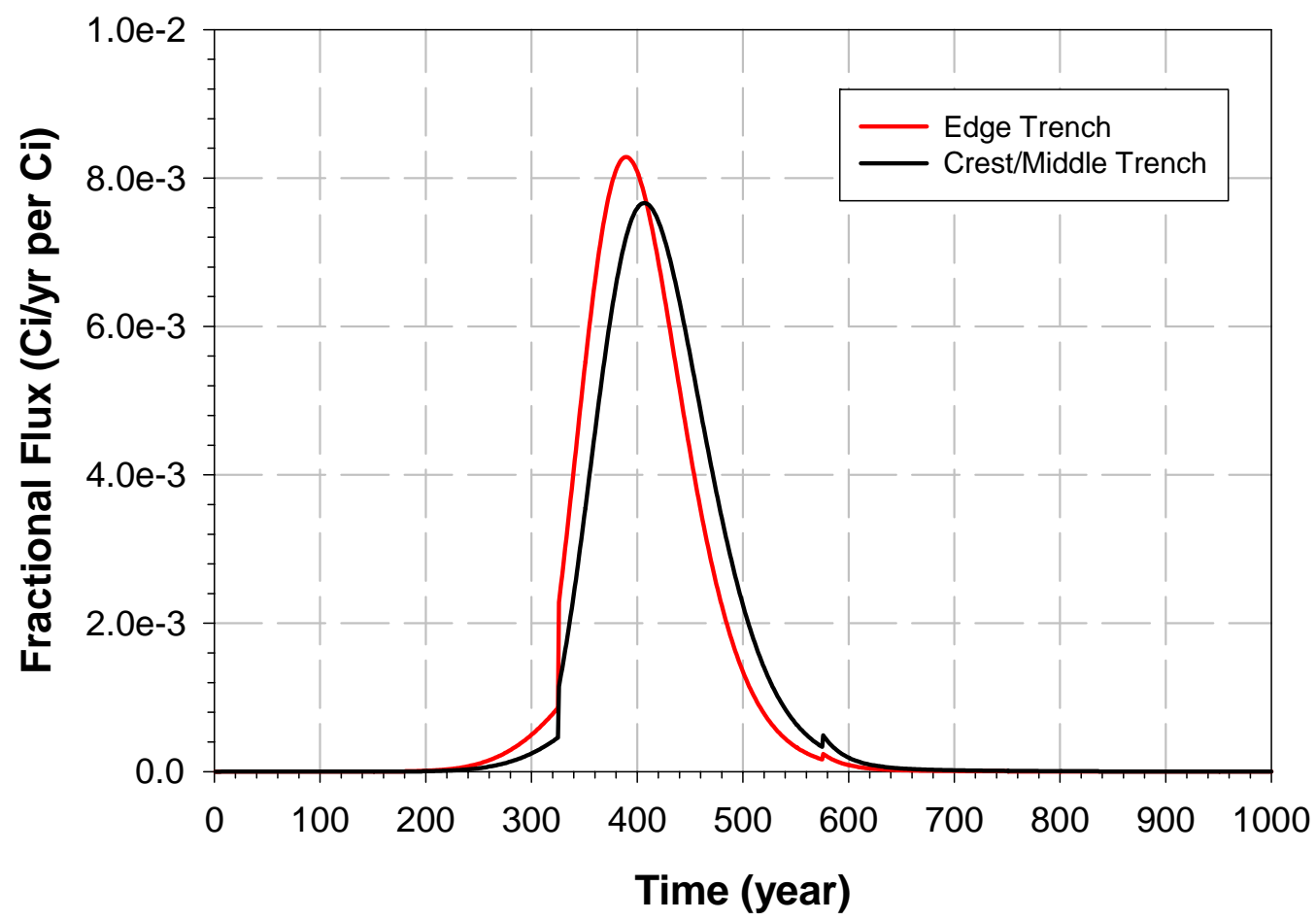

Figure 10. Fractional fluxes at the water table (Base case)

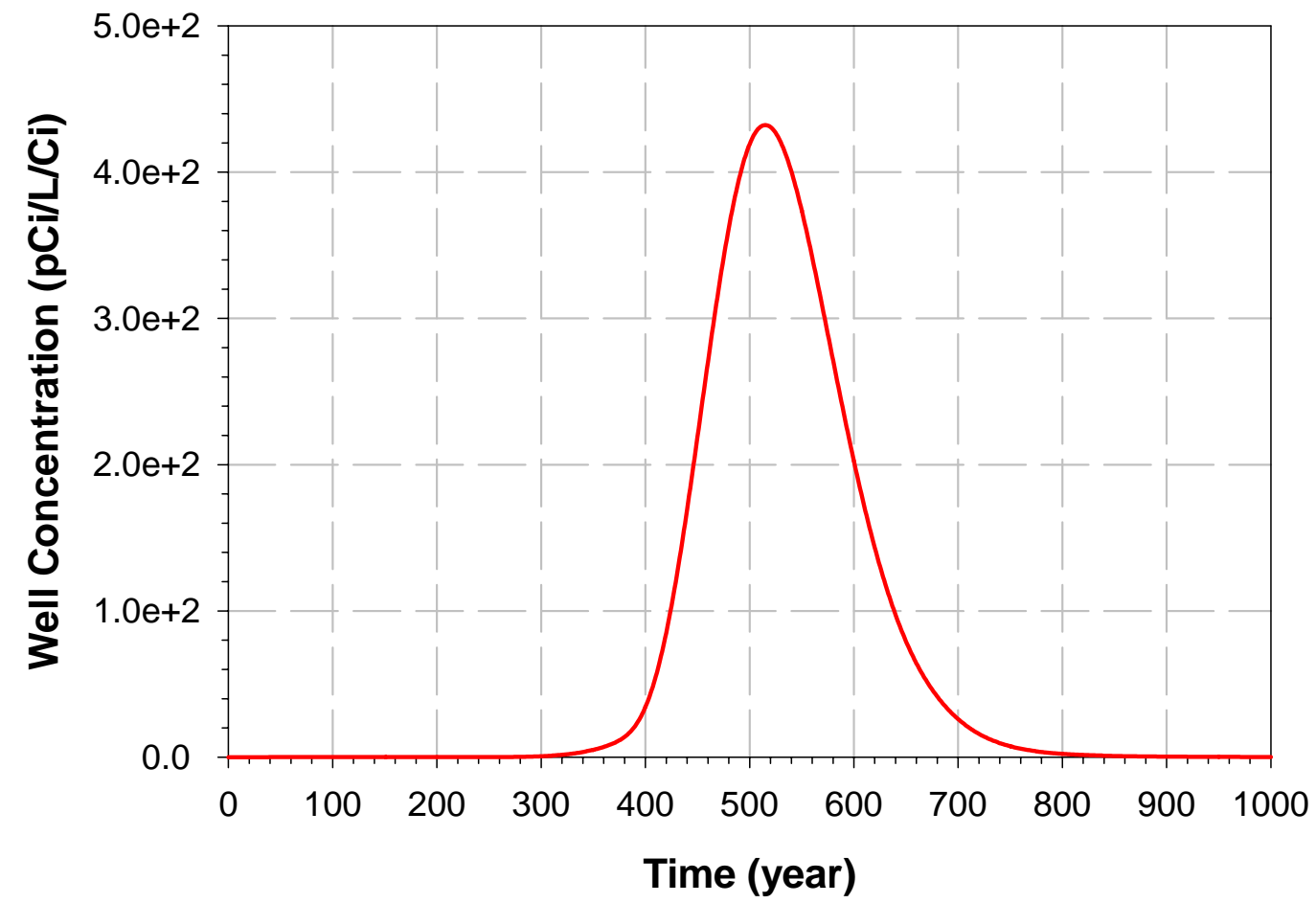

Figure 11. Well concentration (Base case) 
WSRC-TR-2005-00104

Revision 0

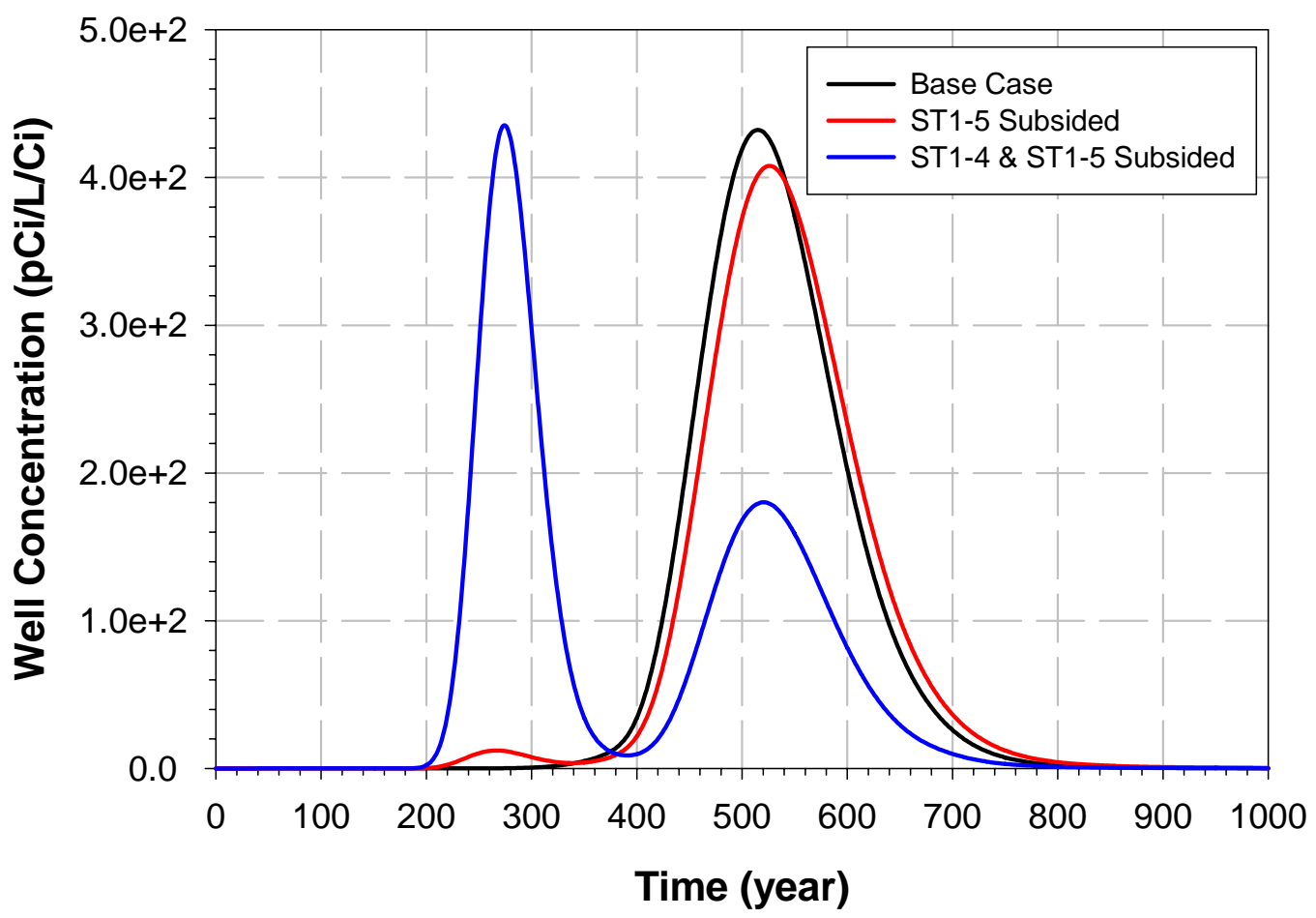

Figure 12. Well concentration (Trench subsidence at 125 years)

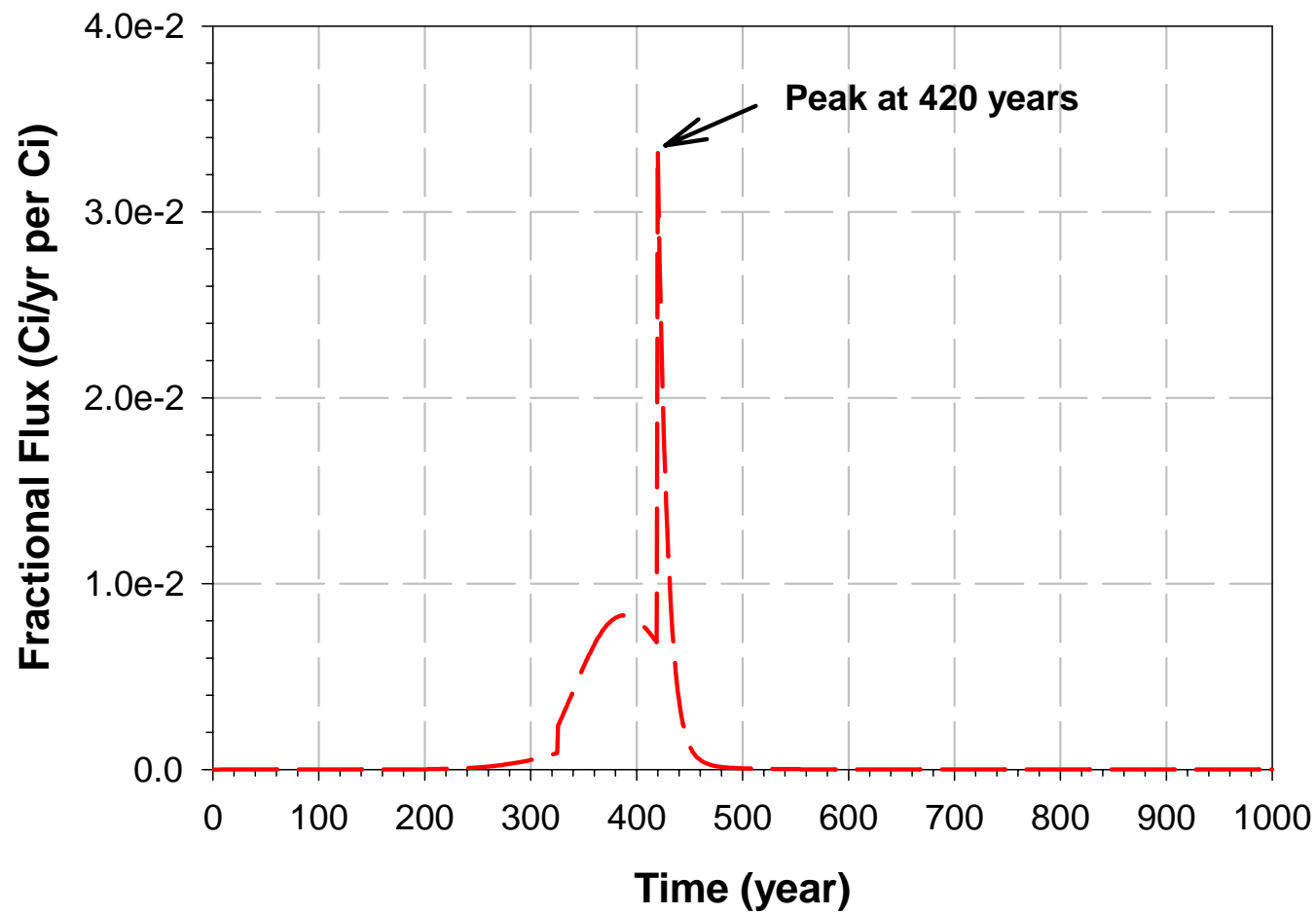

Figure 13. Fractional flux at the water table (ST1-5 subsidence at 419 years) 


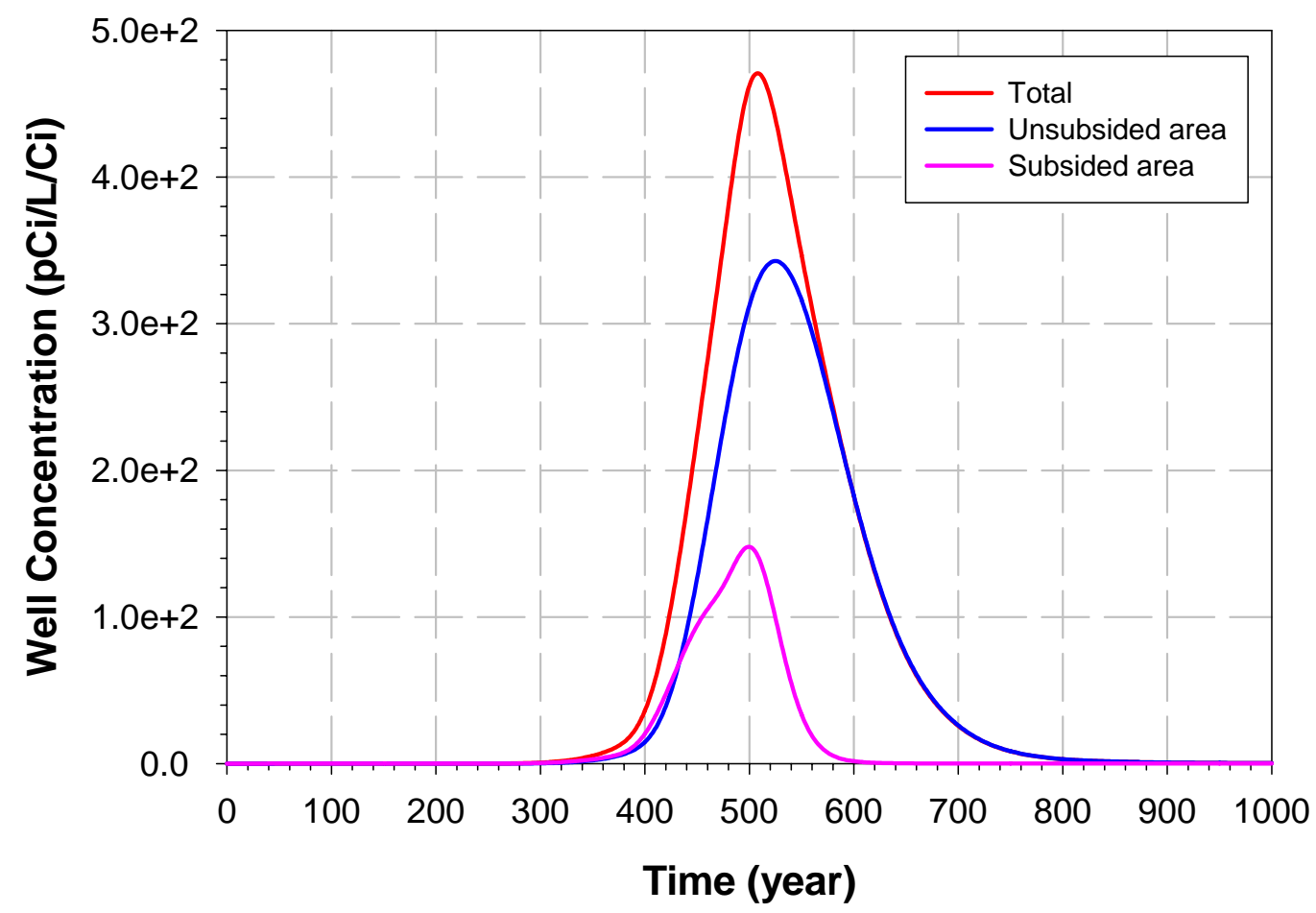

Figure 14. Well concentration (ST1-5 subsidence at 419 years)

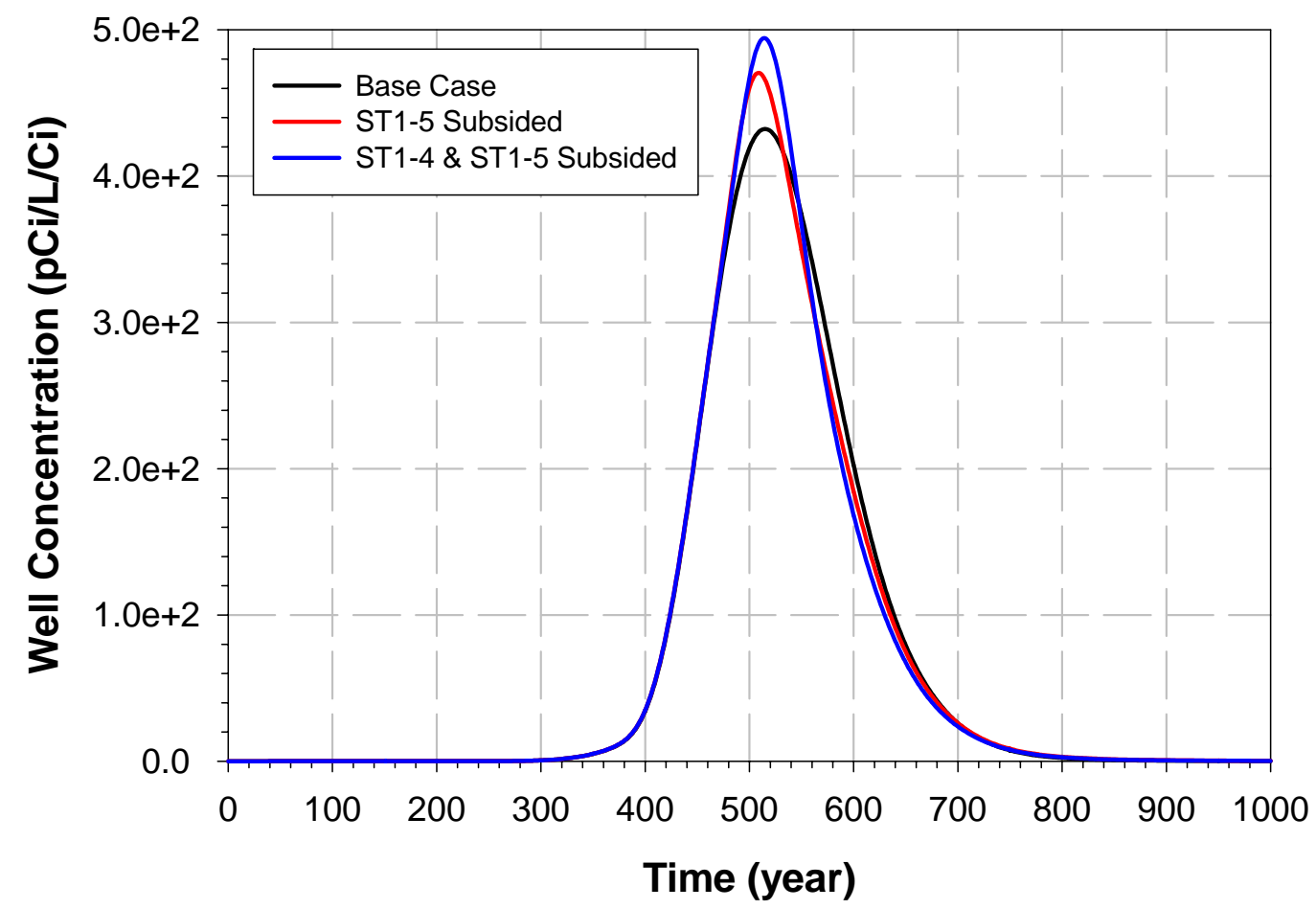

Figure 15. Well concentration (Trench subsidence at 419 years) 
WSRC-TR-2005-00104

Revision 0

Table 3. Summary of peak well concentrations

\begin{tabular}{|c|c|c|c|}
\hline & $\begin{array}{l}\text { Peak Time } \\
\text { (yr) }\end{array}$ & $\begin{array}{l}\text { Peak Concentration } \\
\text { (pCi/L/Ci) }\end{array}$ & $\begin{array}{c}\% \text { of Peak Concentration } \\
\text { exceeding Base Case } \\
\text { Value }^{\dagger} \\
\end{array}$ \\
\hline Base case (Case 1) & 515 & 432 & - \\
\hline $\begin{array}{l}\text { Subsidence @ } 125 \text { years } \\
\text { (Case 2): } \\
\text { - One-trench subsidence } \\
\text { (Trench 14-5) } \\
\text { - Two-trench subsidence } \\
\text { (Trenches 14-4 and } \\
\text { 14-5) }\end{array}$ & $\begin{array}{l}526 \\
274\end{array}$ & $\begin{array}{l}408 \\
435\end{array}$ & $\begin{array}{l}- \\
0.7\end{array}$ \\
\hline $\begin{array}{l}\text { Subsidence @ } 419 \text { years } \\
\text { (Case 3): } \\
\text { - One-trench subsidence } \\
\text { (Trench 14-5) } \\
\text { - Two-trench subsidence } \\
\text { (Trenches 14-4 and } \\
\text { 14-5) }\end{array}$ & $\begin{array}{l}508 \\
514\end{array}$ & $\begin{array}{l}471 \\
495\end{array}$ & $\begin{array}{l}9 \\
15\end{array}$ \\
\hline
\end{tabular}

${ }^{\dagger} 100 *\left(\mathrm{C}-\mathrm{C}_{\text {Base Case }}\right) / \mathrm{C}_{\text {Base Case }}$

\subsection{Evaluation}

a. Is the proposed activity or new information outside the bounds of the approved PA/CA (e.g., does the proposed activity or new information involve a change to the basic disposal concept as described in the PA/CA such as critical inputs/assumptions or an increase in inventory analyzed in the CA)?

No. This activity is bounded by the approved PA/CA and does not involve any changes to the basic disposal concept. Criteria for the waste disposal within an existing disposal unit type were developed.

b. Does the proposed activity or new information cause the PA/CA performance measures to be exceeded?

No. Performance measures are protected by restricting the allowable non-crushable percent area to ensure that peak groundwater contaminant concentrations do not exceed MCLs within a DOE accepted uncertainty in dose impacts (i.e., $\pm 10 \%$ ).

c. Would the radionuclide disposal limits in the approved PA need to be changed to implement the proposed activity?

No. Criteria for the disposal of non-crushable containers with significant internal void space have been developed to ensure that the approved radionuclide disposal limits do not need to be changed.

d. Does the new information involve a change in the radionuclide disposal limits in the approved PA?

No. This unreviewed question relates to a proposed activity as opposed to discovery of new information. This question is addressed for a proposed activity by item $\mathrm{c}$ above. 
e. Does the proposed activity or new information involve a change to the DAS?

No. Since neither the basic disposal concept nor disposal limits are changed from that evaluated in the PA and CA, the Disposal Authorization Statement will not be changed as a result of this proposed activity. 


\section{CONCLUSIONS}

Two scenarios were considered as the high-impact cases for studying the potential effect of trench subsidence on the 100-m well concentrations within 1,000 years. In the first case, trenches subsided right after dynamic compaction (i.e., at 125 years) in order to study when the peak from the subsided area alone would exceed the results from the base case. In the second case, trenches subsided at 419 years to make the peak concentrations from both the subsided and unsubsided areas align in space and time. The simulation results showed that in the first case the subsidence of up to two trenches presented no compliance problem. In the second case, even a single trench subsidence caused the well concentration to exceed the base case value. 
WSRC-TR-2005-00104

Revision 0

THIS PAGE INTENTIONALLY LEFT BLANK 


\section{RECOMMENDATIONS}

The results for both high-impact cases showed an increase in peak concentration for the "worst" contaminant of less than 10 percent when only one individual slit trench subsided. Wilhite (2003) states that "DOE guidance for PA maintenance establishes a criterion for the significance of changes in PA results. The criterion is that changes of about 10 percent in the dose or impact are considered to be insignificant." Using this criterion and the results that neither high-impact case produced concentration increases of ten percent or more for the subsidence of one trench from a combined set of ten trenches, the following general recommendation is made:

1. In general, the amount of the waste area that contains non-crushable containers should not exceed 10 percent for two adjacent Slit Trench disposal units.

This recommendation can be met by assigning the 10 percent limit in any manner across each pair of adjacent Slit Trench disposal units or each individual Slit Trench disposal unit. The waste area is defined as the trench area where waste is disposed, not the overall area of the disposal unit.

Results for subsidence of two slit trenches (20\% of the disposal unit waste area) indicated that the peak concentration for the "worst" contaminant could increase by about $15 \%$. This concentration increase would increase the fraction for that contaminant by $15 \%$. If all disposals only consisted of that contaminant the sum-of-fractions would be 1.15 . To ensure that the sum-of-fractions does not exceed unity, the second specific recommendation is made:

2. If the amount of the waste area that contains non-crushable containers exceeds 10 percent for two adjacent Slit Trench disposal units and requirement 1 above is not satisfied, then the allowable non-crushable percent area can be increased from $10 \%$ to a maximum of $20 \%$. If the allowable non-crushable percent area is increased to more than $10 \%$, then the maximum allowable sum-of-fractions must be reduced by multiplying by $0.87(1 / 1.15)$. This requirement only applies to groundwater pathway time intervals that occur after placement of the final cover (currently 125 years). The groundwater pathway time intervals are as follow:

a. GW1 -0 to 12 years

b. GW2 -12 to 100 years

c. GW3 - 100 to 1000 years.

Therefore, this requirement for current limits only applies to GW3. 
WSRC-TR-2005-00104

Revision 0

THIS PAGE INTENTIONALLY LEFT BLANK 


\section{REFERENCES}

Analytic \& Computational Research, Inc. (ACRi), 2002. PORFLOW' User's Manual, Version 5, Rev. 5.

Collard, L. B., and R. B. Hiergesell, 2004. Special Analysis: 2004 General Revision of Slit and Engineered Trench Limits, WSRC-TR-2004-00300, Revision 0, Westinghouse Savannah River Company, Aiken, South Carolina.

Cook, J. R., M. A. Phifer, E. L. Wilhite, K. E. Young, and W. E. Jones, 2004. Closure Plan for the EArea Low-Level Waste Facility, WSRC-RP-2000-00425, Revision 4, Westinghouse Savannah River Company, Aiken, South Carolina, 106 p.

McDowell-Boyer, L., A. D. Yu, J. R. Cook, D. C. Kocher, E. L. Wilhite, H. Holmes-Burns, and K. E. Young, 2000. Radiological Performance Assessment for the E-Area Low-Level Waste Facility, WSRC-RP-94-218, Revision 1, Westinghouse Savannah River Company, Aiken, South Carolina.

Phifer, M. A., 2003. Saltstone Disposal Facility Mechanically Stabilized Earth Vault Closure Cap Degradation Base Case; Institutional Control to Pine Forest Scenario (U), WSRC-TR-2003-00523, Westinghouse Savannah River Company, Aiken, South Carolina, 162 p.

Phifer, M. A., 2004. Unreviewed Disposal Question Evaluation: Limitations on Slit Trench Disposal of Non-Crushable Containers with Significant Internal Void Space, WSRC-TR-2004-00352, Westinghouse Savannah River Company, Aiken, South Carolina.

Phifer, M. A., 2004a. Preliminary E-Area Trench Closure Cap Closure Sequence, Infiltration, and Waste Thickness (U), WSRC-TR-2004-00119, Westinghouse Savannah River Company, Aiken, South Carolina, $30 \mathrm{p}$.

Phifer, M. A., 2004b. Soil Property and Infiltration Estimates, e-mail to Gregory Flach dated 11/15/04, Westinghouse Savannah River Company, Aiken, South Carolina, 23 p.

Phifer, M. A., 2004c. Preliminary E-Area Intermediate Level Vault Closure Cap Infiltration (U), WSRCTR-2004-00280, Westinghouse Savannah River Company, Aiken, South Carolina, 46 p.

Reed, S. R., 2004. ASBuilt Map, BSRI Layout: R.E.H., Ref. DWG: Site Map 855, Ref. Job: 111403, Rev. 1 - 1/5/04 R.E.H.

US DOE. 1999. Radioactive Waste Management, Office of Environmental Management, US DOE Order 435.1, United States Department of Energy.

US EPA.1994a. The Hydrologic Evaluation of Landfill Performance (HELP) Model User's Guide for Version 3, EPA/600/R-94/168a, Office of Research and Development, United States Environmental Protection Agency, Washington, DC., 94 p.

US EPA 1994b. The Hydrologic Evaluation of Landfill Performance (HELP) Engineering Documentation for Version 3, EPA/600/R-94/168b, Office of Research and Development, United States Environmental Protection Agency, Washington, DC, 116 p. 
Revision 0

Wilhite, E. L., 2003. E-Area Low-Level Waste Facility Performance Assessment Position Paper: Performance Assessment Methodology Development and Implementation of Baseline Changes, WSRC-RP-2003-00390, Revision 0, Westinghouse Savannah River Company, Aiken, South Carolina, February. 


\section{APPENDIX A. E-AREA SLIT TRENCH INFILTRATION ESTIMATES}

Preliminary infiltration estimates for Slit Trenches assuming no subsidence were provided by Phifer (2004a) based upon Phifer (2003). The Slit Trench infiltration estimate during the operational period was modified by Phifer (2004b). These previous infiltration estimates form the basis for the subsided infiltration estimates presented herein. Table A-1 provides the intact infiltration estimates produced from these sources.

Table A-1. Intact slit trench infiltration

\begin{tabular}{|l|l|l|l|l|}
\hline \multicolumn{1}{|c|}{ Year } & \multicolumn{1}{|c|}{$\begin{array}{c}\text { Runoff } \\
\text { (in/yr) }\end{array}$} & $\begin{array}{c}\text { Lateral } \\
\text { Drainage (in/yr) }\end{array}$ & \multicolumn{1}{|c|}{$\begin{array}{c}\text { Infiltration } \\
\text { (in/yr) }\end{array}$} \\
\hline$-25^{1}$ & Operational & 5.805 & 0 & 11.255 \\
\hline $0^{2}$ & Interim Cover & NA & NA & 0.36 \\
\hline $100^{3}$ & Final Cover & 0.154 & 13.70162 & 0.41335 \\
\hline $300^{3}$ & Final Cover & 0.153 & 11.06777 & 3.04724 \\
\hline $550^{3}$ & Final Cover & 0.153 & 6.21423 & 7.89958 \\
\hline $1,000^{3}$ & Final Cover & 0.153 & 2.07646 & 12.0371 \\
\hline $1,800^{3}$ & Final Cover & 0.153 & 0.35957 & 13.76236 \\
\hline $3,400^{3}$ & Final Cover & 0.153 & 0.09355 & 14.03487 \\
\hline $5,600^{3}$ & Final Cover & 0.155 & 0.0557 & 14.07915 \\
\hline $10,000^{3}$ & Final Cover & 0.181 & 0.03075 & 14.09278 \\
\hline
\end{tabular}

${ }^{1}$ Phifer 2004b; ${ }^{2}$ Phifer 2004a; ${ }^{3}$ Phifer 2003 and Phifer 2004a

Preliminary infiltration estimates are provided herein for Slit Trenches assuming subsidence per the method outlined by Phifer (2004c). The following are the primary assumptions associated with these preliminary infiltration estimates:

- It is assumed that 5 Slit Trenches each 20 feet wide by 656 feet long with 10 feet of virgin soil between trenches are covered with a final closure cap whose crest is oriented longitudinally along the center line of the center trench.

- It is assumed that subsidence during the operational and interim cover periods is repaired and does not change the infiltration rates.

- It is assumed that subsidence results in the cover layers remaining distinct and in the same order.

- It is assumed that the same type of cap degradation continues at the same rate in subsided areas as in non-subsided areas.

- It is assumed that ponding within the subsided areas does not occur, because it is assumed that adequate infiltration will occur either downward or through the adjacent virgin soil to prevent ponding.

- It is assumed that down slope subsidence does not produce significant runon to the up slope subsided area of interest.

At collapse of the non-crushable containers with significant internal void space due to corrosion and subsequent structural failure the following are conservatively assumed:

- Subsidence of the overlying closure cap will occur,

- Closure cap subsidence results in the cap losing its runoff and drainage layer functionality and a decrease in evapotranspiration in the subsided area, and 
- Increased infiltration will occur through that portion of the closure cap overlying the collapsed area.

The HELP modeling performed by Phifer (2003) has been used as the basis for the production of infiltration estimates from year 100 to year 10,000. The HELP modeling (Phifer 2003) was primarily revised so that no runoff could occur, the upper drainage layer ceased lateral drainage, and evapotranspiration decreased. The hydraulic properties of the layers have not been changed due to the subsidence. The specific revisions to the referenced HELP modeling include (Phifer 2004c):

- Runoff was prohibited by changing the input for percent of area where runoff is possible from 100 percent to 0 percent and by setting the runoff Curve Number $(\mathrm{CN})$ to 0 .

- Lateral drainage through the upper drainage layer (layer \#5) was ceased, by changing the HELP layer type from 2 (lateral drainage layer) to 1 (vertical percolation layer) and eliminating the associated drainage length and drain slope.

- Evapotranspiration was decreased, by reducing the HELP maximum leaf area index (MLAI) from 3.5 to 1.0 and the evaporative zone depth from 22 inches to 16 inches. A MLAI of 1.0 represents a poor grass cover where the leaf area is equivalent to the ground surface area. So long as surface water ponding does not occur, the MLAI should not be reduced below 1.0 (bare soil has a MLAI of 0). For Augusta an evaporation zone depth of 10 inches represents bare conditions and depth of 22 inches represents fair conditions; therefore the depth was taken to be 16 to represent poor conditions (i.e. halfway between the bare and fair values). (US EPA 1994a; US EPA 1994b)

- Additionally the landfill area was set to the footprint of a single Slit Trench (i.e. $656 \mathrm{ft}$ by $20 \mathrm{ft}$ or 0.3 acres), layer numbers 8 and 9 were deleted, since they are not present in the E-Area closure cap, and the thickness of layer number 7 (i.e. lower backfill) was reduced to 40 inches to be consistent with the closure plan (Cook et al., 2004).

- Runoff and lateral drainage from intact areas upslope of subsided areas for the same year were added together and converted to inflow to the top layer within the down slope subsided areas based upon an inflow area adjustment factor determined by dividing the upslope intact distance by the width of the Slit Trenches (i.e. $20 \mathrm{ft}$ ) (also refer to Figure A-1 and Table A-2 for determination of the inflow area adjustment factor):

- For the crest trench no runoff and lateral drainage from adjacent areas will occur.

- For the middle trench with no upslope subsidence, the distance upslope of the middle trench is 20 $\mathrm{ft}(1 / 2$ the crest trench plus $10 \mathrm{ft}$ of virgin area) and the middle trench is also $20 \mathrm{ft}$ wide, therefore the inflow does not have to be area adjusted.

- For the middle trench with subsidence of the crest trench, the distance upslope of the middle trench to the subsided crest trench is $10 \mathrm{ft}$ and the middle trench is $20 \mathrm{ft}$ wide, therefore the inflow has to be area adjusted by a factor of $10 / 20(0.5)$.

- For the edge trench with no upslope subsidence, the distance upslope of the edge trench is $50 \mathrm{ft}$ and the edge trench is only $20 \mathrm{ft}$ wide, therefore the inflow has to be area adjusted by a factor of $50 / 20(2.5)$.

- For the edge trench with subsidence of the crest trench, the distance upslope of the edge trench to the subsided crest trench is $40 \mathrm{ft}$ and the edge trench is $20 \mathrm{ft}$ wide, therefore the inflow has to be area adjusted by a factor of $40 / 20(2)$.

- For the edge trench with subsidence of the middle trench, the distance upslope of the edge trench to the subsided middle trench is $10 \mathrm{ft}$ and the edge trench is $20 \mathrm{ft}$ wide, therefore the inflow has to be area adjusted by a factor of 10/20 (0.5). The edge trench is not affect by conditions upslope of the subsided middle trench. This is the same area adjustment factor as that for the middle trench with subsidence of the crest trench. Therefore infiltration for the edge trench with subsidence of the middle trench will be the same as that for the middle trench with subsidence of the crest trench. 
- For the edge trench with subsidence of both crest and middle trenches, the distance upslope of the edge trench to the subsided middle trench is $10 \mathrm{ft}$ and the edge trench is $20 \mathrm{ft}$ wide, therefore the inflow has to be area adjusted by a factor of $10 / 20(0.5)$. The edge trench is not affect by conditions upslope of the subsided middle trench. This is the same area adjustment factor as that for the middle trench with subsidence of the crest trench. Therefore infiltration for the edge trench with subsidence of the middle trench will be the same as that for the middle trench with subsidence of the crest trench.

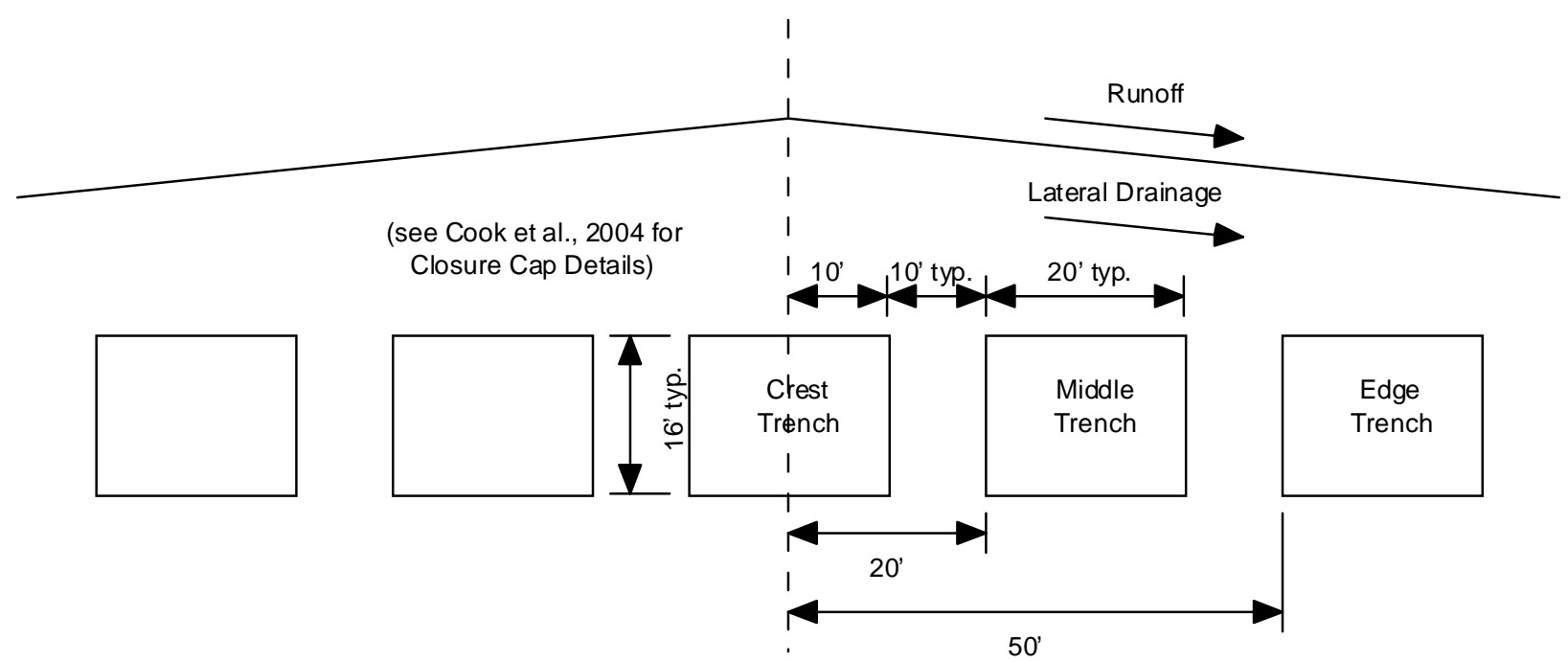

Figure A-1. Slit Trench arrangement

Table A-2. Inflow area adjustment factor

\begin{tabular}{|l|l|l|l|}
\hline Subsided Trench & Upslope Subsidence & $\begin{array}{l}\text { Intact Upslope Length } \\
(\mathrm{ft})\end{array}$ & $\begin{array}{l}\text { Inflow Area } \\
\text { Adjustment Factor }\end{array}$ \\
\hline Crest & Not applicable & Not applicable & Not applicable \\
\hline Middle & None & 20 & $20 / 20=1$ \\
\hline Middle & Crest & 10 & $10 / 20=0.5$ \\
\hline Edge & None & 50 & $50 / 20=2.5$ \\
\hline Edge & Crest & 40 & $40 / 20=2$ \\
\hline Edge & Middle & 10 & $10 / 20=0.5$ \\
\hline Edge & Crest \& middle & 10 & $10 / 20=0.5$ \\
\hline
\end{tabular}

Table A-3 through Table A-9 provide the resulting infiltration estimates for subsided conditions, and Table A-10 provides an infiltration summary. These infiltrations apply to trenches which have subsided fully over their entire width, but can be applied to any length of trench desired.

With subsidence the least amount of infiltration occurs through a subsided crest trench and the greatest amount of infiltration occurs through a subsided edge trench. Additionally ponding is most likely to occur in an edge trench at year 100. These general observations might need to be considered when setting limits for the disposal of non-crushable containers with significant internal void space within Slit Trenches. 
Table A-3. Crest trench subsided infiltration

\begin{tabular}{|l|l|l|l|l|}
\hline Year & \multicolumn{1}{|c|}{ Period } & \multicolumn{1}{c|}{$\begin{array}{c}\text { Runoff } \\
\text { (in/yr) }\end{array}$} & $\begin{array}{c}\text { Lateral } \\
\text { Drainage } \\
\text { (in/yr) }\end{array}$ & Infiltration (in/yr) \\
\hline-25 & Operational & 5.805 & 0 & 11.255 \\
\hline 0 & Interim Cover & NA & NA & 0.36 \\
\hline 100 & Final Cover & 0 & 0 & 15.35101 \\
\hline 300 & Final Cover & 0 & 0 & 15.91374 \\
\hline 550 & Final Cover & 0 & 0 & 15.91282 \\
\hline 1,000 & Final Cover & 0 & 0 & 15.90293 \\
\hline 1,800 & Final Cover & 0 & 0 & 15.88178 \\
\hline 3,400 & Final Cover & 0 & 0 & 15.81477 \\
\hline 5,600 & Final Cover & 0 & 0 & 15.74556 \\
\hline 10,000 & Final Cover & 0 & 0 & 15.68338 \\
\hline
\end{tabular}

Table A-4. Middle trench subsided infiltration with no upslope subsidence

\begin{tabular}{|l|l|l|l|l|l|}
\hline Year & Period & $\begin{array}{c}\text { Inflow to Top } \\
\text { Layer } \\
\text { (in/yr) }\end{array}$ & $\begin{array}{c}\text { Runoff } \\
\text { (in/yr) }\end{array}$ & $\begin{array}{c}\text { Lateral } \\
\text { Drainage } \\
\text { (in/yr) }\end{array}$ & $\begin{array}{c}\text { Infiltration } \\
\text { (in/yr) }\end{array}$ \\
\hline-25 & Operational & NA & 5.805 & 0 & 11.255 \\
\hline 0 & Interim Cover & NA & NA & NA & 0.36 \\
\hline $1000^{2}$ & Final Cover & 13.85562 & 0 & 0 & 27.35554 \\
\hline 300 & Final Cover & 11.22077 & 0 & 0 & 24.96526 \\
\hline 550 & Final Cover & 6.36723 & 0 & 0 & 20.8031 \\
\hline 1,000 & Final Cover & 2.22946 & 0 & 0 & 17.67164 \\
\hline 1,800 & Final Cover & 0.51257 & 0 & 0 & 16.62701 \\
\hline 3,400 & Final Cover & 0.24655 & 0 & 0 & 16.27673 \\
\hline 5,600 & Final Cover & 0.2107 & 0 & 0 & 16.12043 \\
\hline 10,000 & Final Cover & 0.21175 & 0 & 0 & 16.15502 \\
\hline
\end{tabular}

${ }^{1}$ Inflow to Top Layer $=$ Table A-1 Runoff + Table A-1 Lateral Drainage

${ }^{2}$ Used 100 year inflow and 300 year soil conditions due to excessive saturation 
Table A-5. Middle trench subsided infiltration with subsidence of the crest trench

\begin{tabular}{|l|l|l|l|l|l|}
\hline Year & Period & $\begin{array}{c}\text { Inflow to Top } \\
\text { Layer } \\
\text { (in/yr) }\end{array}$ & $\begin{array}{c}\text { Runoff } \\
\text { (in/yr) }\end{array}$ & $\begin{array}{c}\text { Lateral } \\
\text { Drainage } \\
\text { (in/yr) }\end{array}$ & $\begin{array}{c}\text { Infiltration } \\
\text { (in/yr) }\end{array}$ \\
\hline-25 & Operational & NA & 5.805 & 0 & 11.255 \\
\hline 0 & Interim Cover & NA & NA & NA & 0.36 \\
\hline $100^{2}$ & Final Cover & 6.92781 & 0 & 0 & 21.27118 \\
\hline 300 & Final Cover & 5.610385 & 0 & 0 & 20.19972 \\
\hline 550 & Final Cover & 3.183615 & 0 & 0 & 18.36486 \\
\hline 1,000 & Final Cover & 1.11473 & 0 & 0 & 17.00104 \\
\hline 1,800 & Final Cover & 0.256285 & 0 & 0 & 16.42927 \\
\hline 3,400 & Final Cover & 0.123275 & 0 & 0 & 16.2403 \\
\hline 5,600 & Final Cover & 0.10535 & 0 & 0 & 16.13 \\
\hline 10,000 & Final Cover & 0.105875 & 0 & 0 & 16.1351 \\
\hline
\end{tabular}

${ }^{1}$ Inflow to Top Layer $=($ Table A-1 Runoff + Table A-1 Lateral Drainage $) \times 0.5$

${ }^{2}$ Used 100 year inflow and 300 year soil conditions due to excessive saturation

Table A-6. Edge trench subsided infiltration with no upslope subsidence

\begin{tabular}{|l|l|l|l|l|l|}
\hline Year & Period & $\begin{array}{c}\text { Inflow to Top } \\
\text { Layer } \\
\text { (in/yr) }\end{array}$ & $\begin{array}{c}\text { Runoff } \\
\text { (in/yr) }\end{array}$ & $\begin{array}{c}\text { Lateral } \\
\text { Drainage } \\
\text { (in/yr) }\end{array}$ & $\begin{array}{c}\text { Infiltration } \\
\text { (in/yr) }\end{array}$ \\
\hline-25 & Operational & NA & 5.805 & 0 & 11.255 \\
\hline 0 & Interim Cover & NA & NA & NA & 0.36 \\
\hline $100^{2}$ & Final Cover & 34.63905 & 0 & 0 & 47.7733 \\
\hline 300 & Final Cover & 28.05193 & 0 & 0 & 41.1845 \\
\hline 550 & Final Cover & 15.91808 & 0 & 0 & 29.28333 \\
\hline 1,000 & Final Cover & 5.57365 & 0 & 0 & 20.14728 \\
\hline 1,800 & Final Cover & 1.281425 & 0 & 0 & 16.94936 \\
\hline 3,400 & Final Cover & 0.616375 & 0 & 0 & 16.4594 \\
\hline 5,600 & Final Cover & 0.52675 & 0 & 0 & 16.26553 \\
\hline 10,000 & Final Cover & 0.529375 & 0 & 0 & 16.44462 \\
\hline
\end{tabular}

${ }^{1}$ Inflow to Top Layer $=($ Table A-1 Runoff + Table A-1 Lateral Drainage $) \times 2.5$

${ }^{2}$ Used 100 year inflow and 300 year soil conditions due to excessive saturation 
Table A-7. Edge trench subsided infiltration with subsidence of the crest trench

\begin{tabular}{|l|l|l|l|l|l|}
\hline Year & Period & $\begin{array}{c}\text { Inflow to Top } \\
\text { Layer }^{1} \\
\text { (in/yr) }\end{array}$ & $\begin{array}{c}\text { Runoff } \\
\text { (in/yr) }\end{array}$ & $\begin{array}{c}\text { Lateral } \\
\text { Drainage } \\
\text { (in/yr) }\end{array}$ & $\begin{array}{c}\text { Infiltration } \\
\text { (in/yr) }\end{array}$ \\
\hline-25 & Operational & NA & 5.805 & 0 & 11.255 \\
\hline 0 & Interim Cover & NA & NA & NA & 0.36 \\
\hline $100^{2}$ & Final Cover & 27.71124 & 0 & 0 & 40.84586 \\
\hline 300 & Final Cover & 22.44154 & 0 & 0 & 35.59461 \\
\hline 550 & Final Cover & 12.73446 & 0 & 0 & 26.35596 \\
\hline 1,000 & Final Cover & 4.45892 & 0 & 0 & 19.28921 \\
\hline 1,800 & Final Cover & 1.02514 & 0 & 0 & 16.83654 \\
\hline 3,400 & Final Cover & 0.4931 & 0 & 0 & 16.43844 \\
\hline 5,600 & Final Cover & 0.4214 & 0 & 0 & 16.24025 \\
\hline 10,000 & Final Cover & 0.4235 & 0 & 0 & 16.30297 \\
\hline
\end{tabular}

${ }^{1}$ Inflow to Top Layer $=($ Table A-1 Runoff + Table A-1 Lateral Drainage $) \times 2$

${ }^{2}$ Used 100 year inflow and 300 year soil conditions due to excessive saturation

Table A-8. Edge trench subsided infiltration with subsidence of the middle trench ${ }^{\mathbf{1}}$

\begin{tabular}{|l|l|l|l|l|l|}
\hline Year & Period & $\begin{array}{c}\text { Inflow to } \\
\text { Top Layer } \\
\text { (in/yr) }\end{array}$ & $\begin{array}{c}\text { Runoff } \\
\text { (in/yr) }\end{array}$ & $\begin{array}{c}\text { Lateral } \\
\text { Drainage } \\
\text { (in/yr) }\end{array}$ & $\begin{array}{c}\text { Infiltration } \\
\text { (in/yr) }\end{array}$ \\
\hline-25 & Operational & NA & 5.805 & 0 & 11.255 \\
\hline 0 & Interim Cover & NA & NA & NA & 0.36 \\
\hline 100 & Final Cover & 6.92781 & 0 & 0 & 21.27118 \\
\hline 300 & Final Cover & 5.610385 & 0 & 0 & 20.19972 \\
\hline 550 & Final Cover & 3.183615 & 0 & 0 & 18.36486 \\
\hline 1,000 & Final Cover & 1.11473 & 0 & 0 & 17.00104 \\
\hline 1,800 & Final Cover & 0.256285 & 0 & 0 & 16.42927 \\
\hline 3,400 & Final Cover & 0.123275 & 0 & 0 & 16.2403 \\
\hline 5,600 & Final Cover & 0.10535 & 0 & 0 & 16.13 \\
\hline 10,000 & Final Cover & 0.105875 & 0 & 0 & 16.1351 \\
\hline
\end{tabular}

${ }^{1}$ Same as for Table A-4, Middle trench subsided infiltration with subsidence of the crest trench 
WSRC-TR-2005-00104

Revision 0

Table A-9. Edge trench subsided infiltration with subsidence of both the crest and middle trenches 1

\begin{tabular}{|l|l|l|l|l|l|}
\hline Year & Period & $\begin{array}{c}\text { Inflow to } \\
\text { Top Layer } \\
\text { (in/yr) }\end{array}$ & $\begin{array}{c}\text { Runoff } \\
\text { (in/yr) }\end{array}$ & $\begin{array}{c}\text { Lateral } \\
\text { Drainage } \\
\text { (in/yr) }\end{array}$ & $\begin{array}{c}\text { Infiltration } \\
\text { (in/yr) }\end{array}$ \\
\hline-25 & Operational & NA & 5.805 & 0 & 11.255 \\
\hline 0 & Interim Cover & NA & NA & NA & 0.36 \\
\hline 100 & Final Cover & 6.92781 & 0 & 0 & 21.27118 \\
\hline 300 & Final Cover & 5.610385 & 0 & 0 & 20.19972 \\
\hline 550 & Final Cover & 3.183615 & 0 & 0 & 18.36486 \\
\hline 1,000 & Final Cover & 1.11473 & 0 & 0 & 17.00104 \\
\hline 1,800 & Final Cover & 0.256285 & 0 & 0 & 16.42927 \\
\hline 3,400 & Final Cover & 0.123275 & 0 & 0 & 16.2403 \\
\hline 5,600 & Final Cover & 0.10535 & 0 & 0 & 16.13 \\
\hline 10,000 & Final Cover & 0.105875 & 0 & 0 & 16.1351 \\
\hline
\end{tabular}

${ }^{1}$ Same as for Table A-4, Middle trench subsided infiltration with subsidence of the crest trench 
WSRC-TR-2005-00104

Revision 0

Table A-10. Infiltration summary

\begin{tabular}{|c|c|c|c|c|c|c|c|c|c|}
\hline Year & Period & $\begin{array}{c}\text { Intact } \\
\text { Conditions } \\
(\mathrm{in} / \mathrm{yr})\end{array}$ & $\begin{array}{c}\text { Crest Trench } \\
\text { Subsided } \\
\text { Infiltration } \\
\text { (in/yr) }\end{array}$ & $\begin{array}{c}\text { Middle } \\
\text { Trench } \\
\text { Subsided } \\
\text { Infiltration } \\
\text { with No } \\
\text { Upslope } \\
\text { Subsidence } \\
\text { (in/yr) }\end{array}$ & $\begin{array}{c}\text { Middle } \\
\text { Trench } \\
\text { Subsided } \\
\text { Infiltration } \\
\text { with } \\
\text { Subsidence } \\
\text { of the Crest } \\
\text { Trench } \\
\text { (in/yr) }\end{array}$ & $\begin{array}{c}\text { Edge Trench } \\
\text { Subsided } \\
\text { Infiltration } \\
\text { with No } \\
\text { Upslope } \\
\text { Subsidence } \\
\text { (in/yr) }\end{array}$ & $\begin{array}{c}\text { Edge Trench } \\
\text { Subsided } \\
\text { Infiltration } \\
\text { with } \\
\text { Subsidence } \\
\text { of the Crest } \\
\text { Trench } \\
\text { (in/yr) }\end{array}$ & $\begin{array}{c}\text { Edge Trench } \\
\text { Subsided } \\
\text { Infiltration } \\
\text { with } \\
\text { Subsidence } \\
\text { of the Middle } \\
\text { Trench } \\
\text { (in/yr) }\end{array}$ & $\begin{array}{c}\text { Edge Trench } \\
\text { Subsided } \\
\text { Infiltration } \\
\text { with } \\
\text { Subsidence } \\
\text { of both the } \\
\text { Crest and } \\
\text { Middle } \\
\text { Trenches } \\
\text { (in/yr) }\end{array}$ \\
\hline-25 & Operational & 11.255 & 11.255 & 11.255 & 11.255 & 11.255 & 11.255 & 11.255 & 11.255 \\
\hline 0 & $\begin{array}{l}\text { Interim } \\
\text { Cover }\end{array}$ & 0.36 & 0.36 & 0.36 & 0.36 & 0.36 & 0.36 & 0.36 & 0.36 \\
\hline 100 & Final Cover & 0.41335 & 15.35101 & 27.3554 & 21.27118 & 47.7733 & 40.84586 & 21.27118 & 21.27118 \\
\hline 300 & Final Cover & 3.04724 & 15.91374 & 24.96526 & 20.19972 & 41.1845 & 35.59461 & 20.19972 & 20.19972 \\
\hline 550 & Final Cover & 7.89958 & 15.91282 & 20.8031 & 18.36486 & 29.28333 & 26.35596 & 18.36486 & 18.36486 \\
\hline 1,000 & Final Cover & 12.0371 & 15.90293 & 17.67164 & 17.00104 & 20.14728 & 19.28921 & 17.00104 & 17.00104 \\
\hline 1,800 & Final Cover & 13.76236 & 15.88178 & 16.62701 & 16.42927 & 16.94936 & 16.83654 & 16.42927 & 16.42927 \\
\hline 3,400 & Final Cover & 14.03487 & 15.81477 & 16.27673 & 16.2403 & 16.4594 & 16.43844 & 16.2403 & 16.2403 \\
\hline 5,600 & Final Cover & 14.07915 & 15.74556 & 16.12043 & 16.13 & 16.26553 & 16.24025 & 16.13 & 16.13 \\
\hline 10,000 & Final Cover & 14.09278 & 15.68338 & 16.15502 & 16.1351 & 16.44462 & 16.30297 & 16.1351 & 16.1351 \\
\hline
\end{tabular}




\section{APPENDIX B. DESIGN CHECKS}

\section{Design Check Instructions}

Requirements for performing reviews of technical reports are defined in Procedure Manual E-7, 2.40, Design Verification and Checking, and the complementary manual WSRC-IM-2002-00011, Rev.1, Technical Report Design Check Guidelines, provides additional guidance. General lines of inquiry are defined in Table 1 of the latter.

The specific instructions given below are intended to supplement the general lines of inquiry, rather than constrain the scope of design checking.

\section{Overall Analysis and Technical Report (G.P. Flach)}

A high-level review of the overall analysis and technical report should be conducted to ensure that

a. The conceptual approach is acceptable

b. Critical assumptions have been adequately justified

c. Simulated scenarios are in fact "worst case" or "high-impact cases" as stated

d. Adequate background and introductory discussion are provided

e. Interpretation, conclusions and recommendations are supported by preceding report discussion

\section{PorFlow ${ }^{\mathrm{TM}}$ Implementation of the Models (G. A. Taylor)}

In addition to the high-level review of the overall analysis, a review should be conducted to ensure that the conceptual approach is correctly implemented in PorFlow ${ }^{\mathrm{TM}}$ models and the calculated results are accurately represented in the report. The following specific checks are request.

a. Check to ensure that in vadose-zone flow and transport simulations the PorFlow ${ }^{\mathrm{TM}}$ inputs (i.e., 'geom-edge.dat' and 'geom-middle-crest.dat' files in the folder

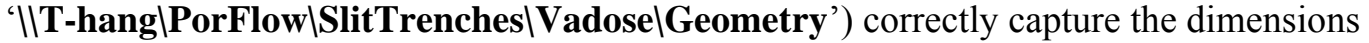
of trenches shown in Figure 2 and Figure 3.

b. Spot check that infiltration rates and material properties shown in Table 1 and Table 2 are accurately transcribed into the PorFlow ${ }^{\mathrm{TM}}$ input files.

c. Spot check that the trench subsidence is modeled correctly by the vadose-zone transport model as described in the report text (for example, change of waste zone thickness and material properties) and the vadose-zone transport model includes the correct flow field for each time interval.

d. Spot check that the source cells shown in Figure 8 are correctly captured in file "IIT-hang $\backslash$ PorFlow $\backslash$ SlitTrenches $\backslash A q u i f e r \backslash S o u r c e s Z o n e . d a t '$

e. Spot check that the source files (i.e., 'ST1-1.src', 'ST1-2.src' etc.) include the correct fluxes at the water table calculated from the vadose-zone transport models (Note: files 'SplitFile01.dat' contain the flux at the water table).

f. Check that a $\mathrm{Kd}$ of $5 \mathrm{ml} / \mathrm{g}$ is used in all aquifer simulations.

g. Check that the PorFlow ${ }^{\mathrm{TM}}$ simulation for the intact condition without dynamic compaction determines the same peak concentration location on the slit trench perimeter as shown in Figure 9 (Note: the result of this simulation is stored in the folder 'IIT-hang \PorFlow $\backslash$ SlitTrenches $\backslash$ Aquifer $\backslash N o C o m p a c t i o n \backslash K d=5 ')$. Also check that the concentration peaks at 420 years on the perimeter.

h. For each aquifer PorFlow ${ }^{\mathrm{TM}}$ simulation, the sources are located in the subfolder 'Sources' of that simulation folder. Spot check that INCLude source filenames are properly 
Revision 0

specified.

i. Spot check convergence for flow (vadose-zone simulations) and mass balance for transport (both vadose-zone and aquifer simulations).

j. Check that Figure 12 and Figure 15 accurately represent the PorFlow ${ }^{\mathrm{TM}}$ results. 
WSRC-TR-2005-00104

Revision 0

\section{Responses to Design Checking Comments for Overall Analysis and Technical Report (G.P. Flach)}

Thong,

I reviewed WSRC-TR-2005-00104 per the design check instructions included as Appendix B in the draft provided. The overall analysis and conceptual approach described in the report are technically sound, and I have only editorial suggestions to improve the text:

1) Introduction - suggest mentioning that subsidence concentrates waste in the lower portion of the trench, increasing concentration, in addition to increasing infiltration.

A sentence to describe the waste zone reduction after subsidence, causing an increase in waste concentration, has been added to text.

2) Table 1 - suggest reporting values to 1 or perhaps 2 decimel places at most, to avoid the implication of more accuracy in the estimates than warranted.

Table 1 and Table A-10 provide infiltration values that were used in PorFlow analyses. Implementation of PorFlow inputs based on these values has been checked by another reviewer. Therefore, changing these values (e.g., reporting only 1 decimal place) may cause some design check conflict.

3) Figure 3 - the horizontal dimension is exaggerated relative to the vertical in the image. suggest setting the $X Y$ aspect ratio to 1:1 in Tecplot, and regenerating the image.

Done.

4) Page 6, second paragraph - I believe $\mathrm{Kd}=0$ was rejected because the peak concentration would occur before dynamic compaction at 125 years. Suggest mentioning that in the paragraph.

The following sentence has been added to text:

"With a zero $\mathrm{Kd}$, the fractional flux peaks at 7 years. Subsidence will not have any significant impact on the well concentrations if the flux peaks prior to placement of the final cap at 125 years."

5) Page 10, last paragraph, first line - The stated assumption of uniform waste distribution and instantaneous disposal should be moved towards the beginning of section 2.3.

Done.

6) Figure 12 - I believe the 3 transients shown in the figure are for different monitoring/100 meter well locations. That explains the different behavior observed between cases. Suggest providing an explanation along these lines in the associated text (specific element or IJK indices would be good).

The following sentences have been added to the end of the third paragraph from the bottom on page 11: 
"In Figure 12, to capture the peak concentrations, the well concentrations were appropriately monitored at different well locations, i.e., at element 45021 for the base case, at element 41128 for the ST1-5 subsidence, and at element 44657 for the ST1-4/ST1-5 subsidence. As a result, the different behavior was observed between cases."

Greg 


\section{Responses to Design Checking Comments for PorFlow Implementation of the Models (G.A. Taylor)}

\section{PorFlow ${ }^{\mathrm{TM}}$ Implementation of the Models (G. A. Taylor)}

In addition to the high-level review of the overall analysis, a review should be conducted to ensure that the conceptual approach is correctly implemented in PorFlow ${ }^{\mathrm{TM}}$ models and the calculated results are accurately represented in the report. The following specific checks are request. Reviewer's comments are in italics.

a. Check to ensure that in vadose-zone flow and transport simulations the PorFlow ${ }^{\mathrm{TM}}$ inputs (i.e., 'geom-edge.dat' and 'geom-middle-crest.dat' files in the folder

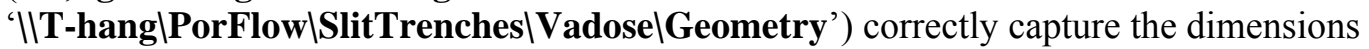
of trenches shown in Figure 2 and Figure 3.

The geometry files were checked and correctly represent the two trenches.

b. Spot check that infiltration rates and material properties shown in Table 1 and Table 2 are accurately transcribed into the PorFlow ${ }^{\mathrm{TM}}$ input files.

The material properties were checked and modeled correctly. The infiltration rates were checked and seen to be correct. A question come up about the Intact|125-325|crest-middlelcompaction (and all other "compaction" runs in the Intact tree) infiltration rates. An infiltration rate corresponding to no subsidence (3.05 in/yr) was used. This usage was explained and is correct.

c. Spot check that the trench subsidence is modeled correctly by the vadose-zone transport model as described in the report text (for example, change of waste zone thickness and material properties) and the vadose-zone transport model includes the correct flow field for each time interval.

The files checked all correctly modeled the subsidence. The correct nodalization was used along with the correct material properties.

d. Spot check that the source cells shown in Figure 8 are correctly captured in file "IIT-hang \PorFlow $\backslash$ SlitTrenches $\backslash$ Aquifer\SourcesZone.dat'

The source cells were spot checked and are correct captured in the file.

e. Spot check that the source files (i.e., 'ST1-1.src', 'ST1-2.src' etc.) include the correct fluxes at the water table calculated from the vadose-zone transport models (Note: files 'SplitFile01.dat' contain the flux at the water table).

The correct source files were used in the files which were spot checked.

f. Check that a $\mathrm{Kd}$ of $5 \mathrm{ml} / \mathrm{g}$ is used in all aquifer simulations.

A $\mathrm{Kd}$ of $5 \mathrm{ml} / \mathrm{g}$ was used.

g. Check that the PorFlow ${ }^{\mathrm{TM}}$ simulation for the intact condition without dynamic compaction determines the same peak concentration location on the slit trench perimeter as shown in Figure 9 (Note: the result of this simulation is stored in the folder ' $\mid \backslash$ T-hang $\backslash$ PorFlow $\backslash$ SlitTrenches $\backslash$ Aquifer $\backslash$ NoCompaction $\backslash K d=5 ')$. Also check that the concentration peaks at 420 years on the perimeter.

The same peak locations were found. The peaks occurred at 420 years.

h. For each aquifer PorFlow ${ }^{\mathrm{TM}}$ simulation, the sources are located in the subfolder 'Sources' of that simulation folder. Spot check that INCLude source filenames are properly specified.

Source filenames were correctly specified for all files spot checked.

i. Spot check convergence for flow (vadose-zone simulations) and mass balance for transport (both vadose-zone and aquifer simulations).

Since the mass balance has been of some concern in past analyses a script was written so that the mass balance and convergence could be easily examined for all runs in the analysis. The mass discrepancies were seen to vary between 9 and 14 orders of magnitude less than the totals. 
WSRC-TR-2005-00104

Revision 0

The convergence was checked by differencing the values of the "Convergence Index" for the last two iterations. For the Aquifer and VadoselTransport series of runs the difference was of the oder of magnitude of 1.0e-15 or less. For the VadoselFlow series the difference was of the order of magnitude of 1.0e-4 to $1.0 e-5$.

From this one can conclude that there is a mass balance along with a reasonably converged solution. (See below)

j. Check that Figure 12 and Figure 15 accurately represent the PorFlow ${ }^{\mathrm{TM}}$ results.

Figures 12-15 accurately represent the results of the calculations.

Mass balance and convergence check

g:/PorFlow/SlitTrenches/Aquifer/Compaction/Kd=5/run.out

Net flux disparity (Qin-Qout-Qa)......... = 1.776357E-15

Total inflow $($ Qin $=$ Qc in + Qd_in + Qsor $) \ldots=9.995521 \mathrm{E}+00$

Total initial property in region $(\mathrm{Qo}) \ldots=0.000000 \mathrm{E}+00$

Convergence difference last two iterations $=-1.01611999999996 \mathrm{e}-016$

g:/PorFlow/SlitTrenches/Aquifer/NoCompaction/Kd=5/run.out

Net flux disparity (Qin-Qout-Qa)......... $=-3.552714 \mathrm{E}-15$

Total inflow (Qin $=$ Qc_in + Qd_in + Qsor $) \ldots . . .9 .993149 \mathrm{E}+00$

Total initial property in region $(\mathrm{Qo}) \ldots=0.000000 \mathrm{E}+00$

Convergence difference last two iterations $=-1.11645 \mathrm{e}-016$

g:/PorFlow/SlitTrenches/Aquifer/Subsidence/Kd=5/125Yr/ST1-5/run.out

Net flux disparity (Qin-Qout-Qa)......... = -3.552714E-15

Total inflow $($ Qin $=$ Qc_in+Qd_in+Qsor $) \ldots=9.994073 \mathrm{E}+00$

Total initial property in region $(\mathrm{Qo}) \ldots . .=0.000000 \mathrm{E}+00$

Convergence difference last two iterations $=-1.13066 \mathrm{e}-016$

$\mathrm{g}: /$ PorFlow/SlitTrenches/Aquifer/Subsidence/Kd=5/125Yr/ST1-5\&ST1-4/run.out

Net flux disparity (Qin-Qout-Qa)......... $=-1.243450 \mathrm{E}-14$

Total inflow (Qin $=$ Qc_in + Qd_in + Qsor $) \ldots . .=9.994596 \mathrm{E}+00$

Total initial property in region $(\mathrm{Qo}) \ldots . .=0.000000 \mathrm{E}+00$

Convergence difference last two iterations $=-1.08681 \mathrm{e}-016$

g:/PorFlow/SlitTrenches/Aquifer/Subsidence/Kd=5/418Yr/ST1-5/run.out

Net flux disparity (Qin-Qout-Qa)......... $=-1.598721 \mathrm{E}-14$

Total inflow (Qin $=$ Qc in + Qd in + Qsor $) \ldots=9.978841 \mathrm{E}+00$

Total initial property in region $(\mathrm{Qo}) \ldots . .=0.000000 \mathrm{E}+00$

Convergence difference last two iterations $=-1.12846 \mathrm{e}-016$

g:/PorFlow/SlitTrenches/Aquifer/Subsidence/Kd=5/418Yr/ST1-5/SubsidedAreaOnly/run.out

Net flux disparity (Qin-Qout-Qa)......... $=-2.775558 \mathrm{E}-15$

Total inflow (Qin $=$ Qc_in + Qd_in + Qsor) $). . .=9.850459 \mathrm{E}-01$

Total initial property in region $(\mathrm{Qo}) \ldots . .=0.000000 \mathrm{E}+00$

Convergence difference last two iterations $=-2.68724 \mathrm{e}-019$

$\mathrm{g}: /$ PorFlow/SlitTrenches/Aquifer/Subsidence/Kd=5/418Yr/ST1-5/UnsubsidedAreaOnly/run.out

Net flux disparity (Qin-Qout-Qa)........ = 1.953993E-14

Total inflow (Qin $=$ Qc_in + Qd_in + Qsor $) \ldots=8.993795 \mathrm{E}+00$

Total initial property in region $(\mathrm{Qo}) \ldots=0.000000 \mathrm{E}+00$

Convergence difference last two iterations $=-1.13033 \mathrm{e}-016$

$\mathrm{g}: /$ PorFlow/SlitTrenches/Aquifer/Subsidence/Kd=5/418Yr/ST1-5\&ST1-4/run.out

Net flux disparity (Qin-Qout-Qa)......... = -7.105427E-15

Total inflow $\left(\mathrm{Qin}=\mathrm{Qc}\right.$ _in $+\mathrm{Qd} \_$in + Qsor $) \ldots .=9.980927 \mathrm{E}+00$

Total initial property in region $(\mathrm{Qo}) \ldots=0.000000 \mathrm{E}+00$

Convergence difference last two iterations $=-1.13112 \mathrm{e}-016$

g:/PorFlow/SlitTrenches/Aquifer/Subsidence/Kd=5/419Yr/ST1-5/run.out

Net flux disparity (Qin-Qout-Qa)......... = -1.776357E-14

Total inflow $($ Qin $=$ Qc_in + Qd_in + Qsor $) \ldots=9.978995 \mathrm{E}+00$ 
Total initial property in region $(\mathrm{Qo}) \ldots . .=0.000000 \mathrm{E}+00$

Convergence difference last two iterations $=-1.12002 \mathrm{e}-016$

$\mathrm{g}: /$ PorFlow/SlitTrenches/Aquifer/Subsidence/Kd=5/419Yr/ST1-5/SubsidedAreaOnly/run.out

Net flux disparity (Qin-Qout-Qa)........ $=5.551115 \mathrm{E}-16$

Total inflow (Qin $=$ Qc_in + Qd_in + Qsor) $) \ldots=9.851278 \mathrm{E}-01$

Total initial property in region $(\mathrm{Qo}) \ldots . .=0.000000 \mathrm{E}+00$

Convergence difference last two iterations $=-2.66705 \mathrm{e}-019$

$\mathrm{g}: /$ PorFlow/SlitTrenches/Aquifer/Subsidence/Kd=5/419Yr/ST1-5/UnsubsidedAreaOnly/run.out

Net flux disparity (Qin-Qout-Qa)......... = 1.421085E-14

Total inflow $\left(\mathrm{Qin}=\mathrm{Qc}\right.$ _in $+\mathrm{Qd} \_$in + Qsor $) \ldots . .=8.993867 \mathrm{E}+00$

Total initial property in region $(\mathrm{Qo}) \ldots=0.000000 \mathrm{E}+00$

Convergence difference last two iterations $=-1.13498 \mathrm{e}-016$

g:/PorFlow/SlitTrenches/Aquifer/Subsidence/Kd=5/419Yr/ST1-5\&ST1-4/run.out

Net flux disparity (Qin-Qout-Qa)......... = 1.598721E-14

Total inflow $($ Qin $=$ Qc in + Qd_in + Qsor $) \ldots=9.981063 \mathrm{E}+00$

Total initial property in region $(\mathrm{Qo}) \ldots . .=0.000000 \mathrm{E}+00$

Convergence difference last two iterations $=-1.11771 \mathrm{e}-016$

$\mathrm{g}: /$ PorFlow/SlitTrenches/Vadose/Flow/Crest/125-325Yr/run.out

Net flux disparity (Qin-Qout-Qa)........ $=$ 5.602837E-06

Total inflow $(\mathrm{Qin}=\mathrm{Qc}$ _in $+\mathrm{Qd}$ _in $+\mathrm{Qsor}) \ldots=2.956804 \mathrm{E}+08$

Total initial property in region $(\mathrm{Qo}) \ldots=3.832671 \mathrm{E}+05$

Convergence difference last two iterations $=-3.62719 \mathrm{e}-005$

$\mathrm{g}: /$ PorFlow/SlitTrenches/Vadose/Flow/Crest/325-575Yr/run.out

Net flux disparity (Qin-Qout-Qa)......... $=$ 5.602837E-06

Total inflow $($ Qin $=$ Qc_in + Qd_in + Qsor $) \ldots . .=2.956804 \mathrm{E}+08$

Total initial property in region $(\mathrm{Qo}) \ldots=3.832671 \mathrm{E}+05$

Convergence difference last two iterations $=-3.62719 \mathrm{e}-005$

$\mathrm{g}: /$ PorFlow/SlitTrenches/Vadose/Flow/Crest/575-1025Yr/run.out

Net flux disparity (Qin-Qout-Qa)......... $=-9.059906 \mathrm{E}-06$

Total inflow (Qin = Qc_in+Qd_in+Qsor)... = 2.956699E +08

Total initial property in region (Qo) $\ldots . .=3.832654 \mathrm{E}+05$

Convergence difference last two iterations $=-3.93037 \mathrm{e}-005$

$\mathrm{g}: /$ PorFlow/SlitTrenches/Vadose/Flow/Edge/125-325Yr/run.out

Net flux disparity (Qin-Qout-Qa)......... $=2.384186 \mathrm{E}-06$

Total inflow (Qin = Qc in+Qd_in+Qsor)... = 1.479428E +09

Total initial property in region $(\mathrm{Qo}) \ldots . .=7.571777 \mathrm{E}+05$

Convergence difference last two iterations $=-2.52967 \mathrm{e}-005$

g:/PorFlow/SlitTrenches/Vadose/Flow/Edge/325-575Yr/run.out

Net flux disparity (Qin-Qout-Qa)......... $=2.861023 \mathrm{E}-06$

Total inflow (Qin = Qc in + Qd in + Qsor $) \ldots=1.275405 \mathrm{E}+09$

Total initial property in region $(\mathrm{Qo}) \ldots=7.334694 \mathrm{E}+05$

Convergence difference last two iterations $=-2.50445 \mathrm{e}-005$

g:/PorFlow/SlitTrenches/Vadose/Flow/Edge/575-1025Yr/run.out

Net flux disparity (Qin-Qout-Qa)........ $=6.318092 \mathrm{E}-06$

Total inflow $($ Qin $=$ Qc_in+Qd_in+Qsor) $\ldots . .=9.068361 \mathrm{E}+08$

Total initial property in region $(\mathrm{Qo}) \ldots=6.818652 \mathrm{E}+05$

Convergence difference last two iterations $=-2.6429 \mathrm{e}-005$

g:/PorFlow/SlitTrenches/Vadose/Flow/Edge-Crest/125-325Yr/run.out

Net flux disparity (Qin-Qout-Qa)......... $=-2.002716 \mathrm{E}-05$

Total inflow (Qin $=$ Qc_in + Qd_in + Qsor $) \ldots . .=1.260025 \mathrm{E}+09$

Total initial property in region $(\mathrm{Qo}) \ldots=7.315662 \mathrm{E}+05$

Convergence difference last two iterations $=-2.45794 \mathrm{e}-005$

g:/PorFlow/SlitTrenches/Vadose/Flow/Edge-Crest/325-575Yr/run.out

Net flux disparity (Qin-Qout-Qa)......... = 2.145767E-06

Total inflow (Qin = Qc_in+Qd_in+Qsor)... $=1.102282 \mathrm{E}+09$

Total initial property in region $(\mathrm{Qo}) \ldots=7.107964 \mathrm{E}+05$ 
Convergence difference last two iterations $=-2.83771 \mathrm{e}-005$

$\mathrm{g}: /$ PorFlow/SlitTrenches/Vadose/Flow/Edge-Crest/575-1025Yr/run.out

Net flux disparity (Qin-Qout-Qa)......... $=6.318092 \mathrm{E}-06$

Total inflow (Qin $=$ Qc_in+Qd_in+Qsor)... $=8.161812 \mathrm{E}+08$

Total initial property in region (Qo) $\ldots . .=6.672952 \mathrm{E}+05$

Convergence difference last two iterations $=-2.86867 \mathrm{e}-005$

$\mathrm{g}: /$ PorFlow/SlitTrenches/Vadose/Flow/Edge-Middle/125-325Yr/run.out

Net flux disparity (Qin-Qout-Qa)......... $=-8.583069 \mathrm{E}-06$

Total inflow $($ Qin $=$ Qc in + Qd in + Qsor $) \ldots=6.587191 \mathrm{E}+08$

Total initial property in region $(\mathrm{Qo}) \ldots . .=6.405894 \mathrm{E}+05$

Convergence difference last two iterations $=-3.15525 \mathrm{e}-005$

g:/PorFlow/SlitTrenches/Vadose/Flow/Edge-Middle/325-575Yr/run.out

Net flux disparity (Qin-Qout-Qa)......... = -6.079674E-06

Total inflow $(\mathrm{Qin}=\mathrm{Qc}$ _in + Qd_in + Qsor $) \ldots . .=6.255386 \mathrm{E}+08$

Total initial property in region $(\mathrm{Qo}) \ldots=6.348136 \mathrm{E}+05$

Convergence difference last two iterations $=-2.75754 \mathrm{e}-005$

g:/PorFlow/SlitTrenches/Vadose/Flow/Edge-Middle/575-1025Yr/run.out

Net flux disparity (Qin-Qout-Qa)........ = 1.919270E-05

Total inflow (Qin $=$ Qc_in + Qd_in + Qsor $) \ldots . .=5.687166 \mathrm{E}+08$

Total initial property in region $(\mathrm{Qo}) \ldots . .=6.247556 \mathrm{E}+05$

Convergence difference last two iterations $=-2.94168 \mathrm{e}-005$

$\mathrm{g}: /$ PorFlow/SlitTrenches/Vadose/Flow/Intact/0-25Yr/Crest-Middle/run.out

Net flux disparity (Qin-Qout-Qa)......... $=-9.491146 \mathrm{E}-04$

Total inflow (Qin $=$ Qc_in+Qd_in+Qsor).... $=2.092147 \mathrm{E}+08$

Total initial property in region $(\mathrm{Qo}) \ldots . .=2.915984 \mathrm{E}+05$

Convergence difference last two iterations $=-0.000262614$

$\mathrm{g}: /$ PorFlow/SlitTrenches/Vadose/Flow/Intact/0-25Yr/Edge/run.out

Net flux disparity (Qin-Qout-Qa)......... $=-5.466342 \mathrm{E}-04$

Total inflow (Qin = Qc_in+Qd_in+Qsor)... = 3.486912E +08

Total initial property in region $(\mathrm{Qo}) \ldots=5.068667 \mathrm{E}+05$

Convergence difference last two iterations $=-0.000193343$

g:/PorFlow/SlitTrenches/Vadose/Flow/Intact/125-325Yr/Crest-Middle/Compaction/run.out

Net flux disparity (Qin-Qout-Qa)........ $=-3.866851 \mathrm{E}-05$

Total inflow (Qin $=$ Qc_in + Qd_in + Qsor $) \ldots . .=5.661965 \mathrm{E}+07$

Total initial property in region $(\mathrm{Qo}) \ldots . .=3.470107 \mathrm{E}+05$

Convergence difference last two iterations $=-4.18387 \mathrm{e}-005$

g:/PorFlow/SlitTrenches/Vadose/Flow/Intact/125-325Yr/Crest-Middle/NoCompaction/run.out

Net flux disparity (Qin-Qout-Qa)......... $=-1.876324 \mathrm{E}-03$

Total inflow (Qin $=$ Qc_in + Qd_in + Qsor $) \ldots=5.661965 \mathrm{E}+07$

Total initial property in region $(\mathrm{Qo}) \ldots=2.728177 \mathrm{E}+05$

Convergence difference last two iterations $=-0.000389589$

g:/PorFlow/SlitTrenches/Vadose/Flow/Intact/125-325Yr/Edge/Compaction/run.out

Net flux disparity (Qin-Qout-Qa)........ $=1.050854 \mathrm{E}+00$

Total inflow $($ Qin $=$ Qc_in + Qd_in + Qsor $) \ldots=9.519311 \mathrm{E}+07$

Total initial property in region $(\mathrm{Qo}) \ldots . .=9.053401 \mathrm{E}+05$

Convergence difference last two iterations $=-3.27189 \mathrm{e}-005$

$\mathrm{g}: /$ PorFlow/SlitTrenches/Vadose/Flow/Intact/125-325Yr/Edge/NoCompaction/run.out

Net flux disparity (Qin-Qout-Qa)......... = 1.657188E-03

Total inflow (Qin $=$ Qc_in + Qd_in+Qsor) $\ldots . . .=9.436608 \mathrm{E}+07$

Total initial property in region $(\mathrm{Qo}) \ldots=4.705756 \mathrm{E}+05$

Convergence difference last two iterations $=-0.00027888$

g:/PorFlow/SlitTrenches/Vadose/Flow/Intact/25-125Yr/Crest-Middle/run.out

Net flux disparity (Qin-Qout-Qa)......... $=-2.116657 \mathrm{E}-03$

Total inflow (Qin = Qc_in + Qd_in + Qsor $) \ldots=6.689019 \mathrm{E}+06$

Total initial property in region (Qo) $\ldots=2.674386 \mathrm{E}+05$

Convergence difference last two iterations $=-0.000307472$ 
g:/PorFlow/SlitTrenches/Vadose/Flow/Intact/25-125Yr/Edge/run.out

Net flux disparity (Qin-Qout-Qa)......... = 1.899861E-03

Total inflow $($ Qin $=$ Qc in + Qd_in + Qsor $) \ldots=1.114836 \mathrm{E}+07$

Total initial property in region $(\mathrm{Qo}) \ldots . .=4.605115 \mathrm{E}+05$

Convergence difference last two iterations $=-0.000260732$

g:/PorFlow/SlitTrenches/Vadose/Flow/Intact/325-575Yr/Crest-Middle/Compaction/run.out

Net flux disparity (Qin-Qout-Qa)........ = 2.941489E-05

Total inflow (Qin $=$ Qc in + Qd_in + Qsor $) \ldots=1.468161 \mathrm{E}+08$

Total initial property in region $(\mathrm{Qo}) \ldots=3.598278 \mathrm{E}+05$

Convergence difference last two iterations $=-3.73077 \mathrm{e}-005$

g:/PorFlow/SlitTrenches/Vadose/Flow/Intact/325-575Yr/Crest-Middle/NoCompaction/run.out

Net flux disparity (Qin-Qout-Qa)......... = 1.194894E-03

Total inflow (Qin $=$ Qc_in+Qd_in+Qsor) $\ldots . . .=1.468161 \mathrm{E}+08$

Total initial property in region $(\mathrm{Qo}) \ldots=2.835948 \mathrm{E}+05$

Convergence difference last two iterations $=-0.000276015$

g:/PorFlow/SlitTrenches/Vadose/Flow/Intact/325-575Yr/Edge/Compaction/run.out

Net flux disparity (Qin-Qout-Qa) $\ldots \ldots \ldots . . .=4.857779 \mathrm{E}-05$

Total inflow $($ Qin $=$ Qc_in + Qd_in + Qsor $) \ldots . . .2 .446934 \mathrm{E}+08$

Total initial property in region $(\mathrm{Qo}) \ldots=5.680548 \mathrm{E}+05$

Convergence difference last two iterations $=-3.2104 \mathrm{e}-005$

$\mathrm{g}: /$ PorFlow/SlitTrenches/Vadose/Flow/Intact/325-575Yr/Edge/NoCompaction/run.out

Net flux disparity (Qin-Qout-Qa)......... = -3.156066E-05

Total inflow (Qin $=$ Qc_in + Qd_in + Qsor $) \ldots . .=2.446934 \mathrm{E}+08$

Total initial property in region $(\mathrm{Qo}) \ldots . .=4.912308 \mathrm{E}+05$

Convergence difference last two iterations $=-0.000177786$

g:/PorFlow/SlitTrenches/Vadose/Flow/Intact/575-1025Yr/Crest-Middle/Compaction/run.out

Net flux disparity (Qin-Qout-Qa)......... = -1.070499E-04

Total inflow $($ Qin $=$ Qc in + Qd_in + Qsor $) \ldots=2.238451 \mathrm{E}+08$

Total initial property in region $(\mathrm{Qo}) \ldots=3.717969 \mathrm{E}+05$

Convergence difference last two iterations $=-4.12201 \mathrm{e}-005$

g:/PorFlow/SlitTrenches/Vadose/Flow/Intact/575-1025Yr/Crest-Middle/NoCompaction/run.out

Net flux disparity (Qin-Qout-Qa)........ = 9.276867E-04

Total inflow $($ Qin $=$ Qc_in + Qd_in + Qsor $) \ldots=2.238451 \mathrm{E}+08$

Total initial property in region $(\mathrm{Qo}) \ldots=2.935229 \mathrm{E}+05$

Convergence difference last two iterations $=-0.000256526$

g:/PorFlow/SlitTrenches/Vadose/Flow/Intact/575-1025Yr/Edge/Compaction/run.out

Net flux disparity (Qin-Qout-Qa)......... $=-1.263618 \mathrm{E}-05$

Total inflow (Qin $=$ Qc_in + Qd_in + Qsor $) \ldots . .=3.730752 \mathrm{E}+08$

Total initial property in region $(\mathrm{Qo}) \ldots . .=5.899686 \mathrm{E}+05$

Convergence difference last two iterations $=-3.35752 \mathrm{e}-005$

g:/PorFlow/SlitTrenches/Vadose/Flow/Intact/575-1025Yr/Edge/NoCompaction/run.out

Net flux disparity (Qin-Qout-Qa)......... = -8.121133E-04

Total inflow (Qin $=$ Qc_in + Qd_in + Qsor $) \ldots . . .3 .730752 \mathrm{E}+08$

Total initial property in region $(\mathrm{Qo}) \ldots . .=5.106477 \mathrm{E}+05$

Convergence difference last two iterations $=-0.000205749$

g:/PorFlow/SlitTrenches/Vadose/Flow/Middle/125-325Yr/run.out

Net flux disparity (Qin-Qout-Qa)......... $=-2.074242 \mathrm{E}-05$

Total inflow (Qin $=$ Qc_in+Qd_in+Qsor) $\ldots . .=5.082800 \mathrm{E}+08$

Total initial property in region (Qo)... $=4.151347 \mathrm{E}+05$

Convergence difference last two iterations $=-3.62566 \mathrm{e}-005$

g:/PorFlow/SlitTrenches/Vadose/Flow/Middle/325-575Yr/run.out

Net flux disparity (Qin-Qout-Qa)......... = -5.221367E-05

Total inflow (Qin $=$ Qc_in+Qd_in+Qsor)... $=4.638697 \mathrm{E}+08$

Total initial property in region $(\mathrm{Qo}) \ldots=4.088810 \mathrm{E}+05$

Convergence difference last two iterations $=-3.61225 \mathrm{e}-005$

g:/PorFlow/SlitTrenches/Vadose/Flow/Middle/575-1025Yr/run.out 
Net flux disparity (Qin-Qout-Qa)......... $=1.408458 \mathrm{E}-04$

Total inflow $(\mathrm{Qin}=\mathrm{Qc}$ _in+Qd_in+Qsor)... $=3.865352 \mathrm{E}+08$

Total initial property in region $(\mathrm{Qo}) \ldots=3.974726 \mathrm{E}+05$

Convergence difference last two iterations $=-3.67225 \mathrm{e}-005$

$\mathrm{g}: /$ PorFlow/SlitTrenches/Vadose/Flow/Middle-Crest/125-325Yr/run.out

Net flux disparity (Qin-Qout-Qa)......... = -2.998114E-05

Total inflow (Qin $=$ Qc_in+Qd_in+Qsor)... $=3.952315 \mathrm{E}+08$

Total initial property in region $(\mathrm{Qo}) \ldots . .=3.988082 \mathrm{E}+05$

Convergence difference last two iterations $=-3.89469 \mathrm{e}-005$

$\mathrm{g}: /$ PorFlow/SlitTrenches/Vadose/Flow/Middle-Crest/325-575Yr/run.out

Net flux disparity (Qin-Qout-Qa)......... $=-2.884865 \mathrm{E}-05$

Total inflow (Qin = Qc_in+Qd_in+Qsor)... = 3.753232E +08

Total initial property in region $(\mathrm{Qo}) \ldots=3.957415 \mathrm{E}+05$

Convergence difference last two iterations $=-3.76159 \mathrm{e}-005$

g:/PorFlow/SlitTrenches/Vadose/Flow/Middle-Crest/575-1025Yr/run.out

Net flux disparity (Qin-Qout-Qa)......... $=2.425909 \mathrm{E}-05$

Total inflow (Qin = Qc_in+Qd_in+Qsor)... = 3.412299E +08

Total initial property in region $(\mathrm{Qo}) \ldots=3.904546 \mathrm{E}+05$

Convergence difference last two iterations $=-3.74686 \mathrm{e}-005$

g:/PorFlow/SlitTrenches/Vadose/Transport/Edge/Kd=5/ST1-5(Subsided)/125Yr/run.out

Net flux disparity (Qin-Qout-Qa)......... = -3.126660E-09

Total inflow $($ Qin $=$ Qc in + Qd_in + Qsor $) \ldots=0.000000 \mathrm{E}+00$

Total initial property in region $(\mathrm{Qo}) \ldots . .=1.000000 \mathrm{E}+00$

Convergence difference last two iterations $=-3.67834 \mathrm{e}-030$

g:/PorFlow/SlitTrenches/Vadose/Transport/Edge/Kd=5/ST1-5(Subsided) $/ 325 \mathrm{Yr} /$ run.out

Net flux disparity (Qin-Qout-Qa)......... = -3.124765E-09

Total inflow (Qin $=$ Qc in + Qd_in + Qsor $) \ldots=0.000000 \mathrm{E}+00$

Total initial property in region $(\mathrm{Qo}) \ldots=1.000000 \mathrm{E}+00$

Convergence difference last two iterations $=-7.10344 \mathrm{e}-026$

g:/PorFlow/SlitTrenches/Vadose/Transport/Edge/Kd=5/ST1-5(Subsided)/400Yr/run.out

Net flux disparity (Qin-Qout-Qa)......... $=-3.124425 \mathrm{E}-09$

Total inflow $($ Qin $=$ Qc_in + Qd_in + Qsor $) \ldots=0.000000 \mathrm{E}+00$

Total initial property in region $(\mathrm{Qo}) \ldots=1.000000 \mathrm{E}+00$

Convergence difference last two iterations $=-2.48693 \mathrm{e}-024$

g:/PorFlow/SlitTrenches/Vadose/Transport/Edge/Kd=5/ST1-5(Subsided)/418Yr/run.out

Net flux disparity (Qin-Qout-Qa)......... = -3.124347E-09

Total inflow (Qin $=$ Qc_in + Qd_in + Qsor $) \ldots=0.000000 \mathrm{E}+00$

Total initial property in region $(\mathrm{Qo}) \ldots . .=1.000000 \mathrm{E}+00$

Convergence difference last two iterations $=-1.49007 \mathrm{e}-020$

$\mathrm{g}: /$ PorFlow/SlitTrenches/Vadose/Transport/Edge/Kd=5/ST1-5(Subsided)/419Yr/run.out

Net flux disparity (Qin-Qout-Qa)......... = -3.124363E-09

Total inflow (Qin $=$ Qc_in $+Q d \_$in + Qsor $) \ldots . .=0.000000 \mathrm{E}+00$

Total initial property in region $(\mathrm{Qo}) \ldots=1.000000 \mathrm{E}+00$

Convergence difference last two iterations $=-5.20931 \mathrm{e}-024$

g:/PorFlow/SlitTrenches/Vadose/Transport/Edge-Middle/Kd=5/ST1-5(Subsided)/125Yr/run.out

Net flux disparity (Qin-Qout-Qa)......... = -3.124082E-09

Total inflow $(\mathrm{Qin}=\mathrm{Qc}$ _in + Qd_in + Qsor $) \ldots=0.000000 \mathrm{E}+00$

Total initial property in region $(\mathrm{Qo}) \ldots=1.000000 \mathrm{E}+00$

Convergence difference last two iterations $=-6.05984 \mathrm{e}-025$

$\mathrm{g}: /$ PorFlow/SlitTrenches/Vadose/Transport/Edge-Middle/Kd=5/ST1-5(Subsided)/418Yr/run.out

Net flux disparity (Qin-Qout-Qa)......... = -3.124010E-09

Total inflow $\left(\mathrm{Qin}=\mathrm{Qc} \_\right.$in + Qd_in + Qsor $) \ldots . .=0.000000 \mathrm{E}+00$

Total initial property in region $(\mathrm{Qo}) \ldots=1.000000 \mathrm{E}+00$

Convergence difference last two iterations $=-2.7189 \mathrm{e}-019$

g:/PorFlow/SlitTrenches/Vadose/Transport/Edge-Middle/Kd=5/ST1-5(Subsided)/419Yr/run.out

Net flux disparity (Qin-Qout-Qa)......... = -3.124031E-09 
Total inflow $($ Qin $=$ Qc_in + Qd_in + Qsor $) \ldots=0.000000 \mathrm{E}+00$

Total initial property in region $(\mathrm{Qo}) \ldots=1.000000 \mathrm{E}+00$

Convergence difference last two iterations $=-1.15329 \mathrm{e}-021$

g:/PorFlow/SlitTrenches/Vadose/Transport/Intact/Crest-Middle/Compaction/Kd=5/run.out

Net flux disparity (Qin-Qout-Qa)......... = -1.676763E-09

Total inflow (Qin $=$ Qc_in + Qd_in + Qsor $) \ldots=0.000000 \mathrm{E}+00$

Total initial property in region $(\mathrm{Qo}) \ldots=1.000000 \mathrm{E}+00$

Convergence difference last two iterations $=-2.59638 \mathrm{e}-020$

g:/PorFlow/SlitTrenches/Vadose/Transport/Intact/Crest-Middle/NoCompaction/Kd=5/run.out

Net flux disparity (Qin-Qout-Qa) ......... = -1.676921E-09

Total inflow (Qin $=$ Qc_in + Qd_in + Qsor $) \ldots=0.000000 \mathrm{E}+00$

Total initial property in region $(\mathrm{Qo}) \ldots=1.000000 \mathrm{E}+00$

Convergence difference last two iterations $=-1.18125 \mathrm{e}-018$

g:/PorFlow/SlitTrenches/Vadose/Transport/Intact/Crest-Middle/NoCompaction/Kd=5/Time=125/run.out

Net flux disparity (Qin-Qout-Qa)......... $=-1.676739 \mathrm{E}-09$

Total inflow (Qin $=$ Qc_in + Qd_in + Qsor $) \ldots=0.000000 \mathrm{E}+00$

Total initial property in region $(\mathrm{Qo}) \ldots=1.000000 \mathrm{E}+00$

Convergence difference last two iterations $=-3.92175 \mathrm{e}-016$

g:/PorFlow/SlitTrenches/Vadose/Transport/Intact/Edge/Compaction/Kd=5/run.out

Net flux disparity (Qin-Qout-Qa)......... = -3.123868E-09

Total inflow (Qin $=$ Qc_in + Qd_in + Qsor $) \ldots=0.000000 \mathrm{E}+00$

Total initial property in region $(\mathrm{Qo}) \ldots=1.000000 \mathrm{E}+00$

Convergence difference last two iterations $=-1.10864 \mathrm{e}-020$

g:/PorFlow/SlitTrenches/Vadose/Transport/Intact/Edge/NoCompaction/Kd=10/run.out

Net flux disparity (Qin-Qout-Qa)......... $=-9.123702 \mathrm{E}-12$

Total inflow $\left(\mathrm{Qin}=\mathrm{Qc}\right.$ _in $+\mathrm{Qd} \_$in $\left.+\mathrm{Qsor}\right) \ldots=0.000000 \mathrm{E}+00$

Total initial property in region $(\mathrm{Qo}) \ldots=1.000000 \mathrm{E}+00$

Convergence difference last two iterations $=-8.2718 \mathrm{e}-019$

g:/PorFlow/SlitTrenches/Vadose/Transport/Intact/Edge/NoCompaction/Kd=10/Time=125/run.out

Net flux disparity (Qin-Qout-Qa)......... $=-9.009476 \mathrm{E}-12$

Total inflow $\left(\mathrm{Qin}=\mathrm{Qc}\right.$ _in $+\mathrm{Qd} \_$in $\left.+\mathrm{Qsor}\right) \ldots=0.000000 \mathrm{E}+00$

Total initial property in region $(\mathrm{Qo}) \ldots=1.000000 \mathrm{E}+00$

Convergence difference last two iterations $=-3.17018 \mathrm{e}-016$

g:/PorFlow/SlitTrenches/Vadose/Transport/Intact/Edge/NoCompaction/Kd=100/run.out

Net flux disparity (Qin-Qout-Qa) $\ldots \ldots \ldots . . . .=8.225656 \mathrm{E}-16$

Total inflow $(\mathrm{Qin}=\mathrm{Qc}$ _in $+\mathrm{Qd}$ _in $+\mathrm{Qsor}) \ldots=0.000000 \mathrm{E}+00$

Total initial property in region $(\mathrm{Qo}) \ldots=1.000000 \mathrm{E}+00$

Convergence difference last two iterations $=-3.30764 \mathrm{e}-016$

g:/PorFlow/SlitTrenches/Vadose/Transport/Intact/Edge/NoCompaction/Kd=100/Time=125/run.out

Net flux disparity (Qin-Qout-Qa)......... $=5.124618 \mathrm{E}-16$

Total inflow $(\mathrm{Qin}=\mathrm{Qc}$ in $+\mathrm{Qd}$ in + Qsor $) \ldots=0.000000 \mathrm{E}+00$

Total initial property in region $(\mathrm{Qo}) \ldots=1.000000 \mathrm{E}+00$

Convergence difference last two iterations $=-2.85342 \mathrm{e}-016$

g:/PorFlow/SlitTrenches/Vadose/Transport/Intact/Edge/NoCompaction/Kd=20/run.out

Net flux disparity (Qin-Qout-Qa)......... $=-6.872281 \mathrm{E}-14$

Total inflow (Qin $=$ Qc_in + Qd_in + Qsor $) \ldots . .=0.000000 \mathrm{E}+00$

Total initial property in region $(\mathrm{Qo}) \ldots=1.000000 \mathrm{E}+00$

Convergence difference last two iterations $=-4.06321 \mathrm{e}-017$

g:/PorFlow/SlitTrenches/Vadose/Transport/Intact/Edge/NoCompaction/Kd=20/Time=125/run.out

Net flux disparity (Qin-Qout-Qa)......... = -4.070293E-15

Total inflow (Qin $=$ Qc_in + Qd_in + Qsor $) \ldots=0.000000 \mathrm{E}+00$

Total initial property in region $(\mathrm{Qo}) \ldots . .=1.000000 \mathrm{E}+00$

Convergence difference last two iterations $=-2.91198 \mathrm{e}-016$

$\mathrm{g}$ :/PorFlow/SlitTrenches/Vadose/Transport/Intact/Edge/NoCompaction/Kd=5/run.out

Net flux disparity (Qin-Qout-Qa)......... = -3.124011E-09

Total inflow $($ Qin $=$ Qc_in + Qd_in + Qsor $) \ldots=0.000000 \mathrm{E}+00$ 
Total initial property in region $(\mathrm{Qo}) \ldots . .=1.000000 \mathrm{E}+00$

Convergence difference last two iterations $=-7.92395 \mathrm{e}-019$

$\mathrm{g}: /$ PorFlow/SlitTrenches/Vadose/Transport/Intact/Edge/NoCompaction/Kd=5/Time=125/run.out

Net flux disparity (Qin-Qout-Qa)......... = -3.123845E-09

Total inflow $(\mathrm{Qin}=\mathrm{Qc}$ _in $+\mathrm{Qd}$ _in $+\mathrm{Qsor}) \ldots=0.000000 \mathrm{E}+00$

Total initial property in region $(\mathrm{Qo}) \ldots . .=1.000000 \mathrm{E}+00$

Convergence difference last two iterations $=-3.52676 \mathrm{e}-016$

g:/PorFlow/SlitTrenches/Vadose/Transport/Intact/Edge/NoCompaction/Kd=50/run.out

Net flux disparity (Qin-Qout-Qa) $\ldots \ldots \ldots . . . .=-3.292505 \mathrm{E}-15$

Total inflow (Qin $=$ Qc_in + Qd_in + Qsor $) \ldots=0.000000 \mathrm{E}+00$

Total initial property in region $(\mathrm{Qo}) \ldots=1.000000 \mathrm{E}+00$

Convergence difference last two iterations $=-2.99304 \mathrm{e}-016$

g:/PorFlow/SlitTrenches/Vadose/Transport/Intact/Edge/NoCompaction/Kd=50/Time=125/run.out

Net flux disparity (Qin-Qout-Qa)......... = 1.350982E-16

Total inflow $($ Qin $=$ Qc in + Qd_in + Qsor $) \ldots=0.000000 \mathrm{E}+00$

Total initial property in region $(\mathrm{Qo}) \ldots=1.000000 \mathrm{E}+00$

Convergence difference last two iterations $=-3.0534 \mathrm{e}-016$

g:/PorFlow/SlitTrenches/Vadose/Transport/Middle/Kd=5/ST1-4(Subsided)/125Yr/run.out

Net flux disparity (Qin-Qout-Qa)......... = -1.677187E-09

Total inflow $\left(\mathrm{Qin}=\mathrm{Qc} \_\right.$in $+\mathrm{Qd} \_$in $\left.+\mathrm{Qsor}\right) \ldots . .=0.000000 \mathrm{E}+00$

Total initial property in region $(\mathrm{Qo}) \ldots . .=1.000000 \mathrm{E}+00$

Convergence difference last two iterations $=-1.26304 \mathrm{e}-025$

g:/PorFlow/SlitTrenches/Vadose/Transport/Middle/Kd=5/ST1-4(Subsided)/418Yr/run.out

Net flux disparity (Qin-Qout-Qa)......... = -1.676944E-09

Total inflow (Qin $=$ Qc_in + Qd_in + Qsor $) \ldots=0.000000 \mathrm{E}+00$

Total initial property in region $(\mathrm{Qo}) \ldots=1.000000 \mathrm{E}+00$

Convergence difference last two iterations $=-8.05989 \mathrm{e}-022$

$\mathrm{g}: /$ PorFlow/SlitTrenches/Vadose/Transport/Middle/Kd=5/ST1-4(Subsided)/419Yr/run.out

Net flux disparity (Qin-Qout-Qa)......... $=-1.676969 \mathrm{E}-09$

Total inflow $\left(\mathrm{Qin}=\mathrm{Qc}\right.$ _in $+\mathrm{Qd} \_$in $\left.+\mathrm{Qsor}\right) \ldots=0.000000 \mathrm{E}+00$

Total initial property in region $(\mathrm{Qo}) \ldots=1.000000 \mathrm{E}+00$

Convergence difference last two iterations $=-8.22004 \mathrm{e}-022$ 